\title{
Virtual screening, pharmacokinetics, and molecular dynamics simulations studies to identify potent approved drugs for Chlamydia trachomatis treatment
}

\author{
Emmanuel Israel Edache ${ }^{1 *} \mathbb{D}$, Adamu Uzairu$^{2}$, Gideon Adamu Shallangwa² and Paul Andrew Mamza²
}

\begin{abstract}
Background: The most frequent bacterial sexually transmitted disease is Chlamydia trachomatis (STD). In 2010, the Centers for Disease Control and Prevention (CDC) received 1.3 million reports of cases (CDC). Human chlamydial infections are linked to a variety of clinical symptoms. Inclusion (InCA) membranes are a promising drug target for the treatment of Chlamydia trachomatis. In the present study, molecular docking, ADMET, golden triangle, and molecular dynamics (MD) simulation studies were performed on a series of salicylidene acylhydrazides derivatives against Chlamydia trachomatis. Three types of docking software with different algorithms were used to screen the potential candidate against Chlamydia trachomatis.

Results: The results obtained from the docking analysis succeeded in screening nine novel hit compounds with high affinity to IncA membranes. Then, pharmacokinetics properties were calculated to spot out the drug-likeness of the selected compounds. Also, golden triangles were performed on the selected compounds. Compounds outside the golden triangle indicate that they would have clearance problems. Out of the nine novel hits drugs, four compounds pass the golden triangle screening and virtually all the quality assurance tests proposed by the model and were used for further analysis. One-ns molecular dynamics simulations on the docked complex of compound 44 (one of the highly active selected compounds of the dataset) aided in the further exploration of the binding interactions. Some crucial residues such as Ser111, Gln114, Asn107, Leu142, Gly144, Gln143, Lys104, Tyr149, Phe108, Phe145, and Arg146 were identified. Conventional and carbon-hydrogen bond interactions with amino residues Arg146, Asn107, Phe145, and Ser111 were critical for the binding of inclusion (InCA) membranes inhibitors.
\end{abstract}

Conclusion: Outcomes of the study can further be exploited to develop potent inclusion (IncA) membranes inhibitors.

Keywords: Molecular docking, iGemDock, MVD, AutoDock Vina, ADMET, Golden triangle, Chlamydia trachomatis, Salicylidene acylhydrazides derivatives, MDs simulations

\footnotetext{
*Correspondence: edacheson2004@gmail.com

1 Department of Pure and Applied Chemistry, Faculty of Science,

University of Maiduguri, P.M.B. 1069, Maiduguri, Borno State, Nigeria

Full list of author information is available at the end of the article
}

\begin{abstract}
Background
Chlamydia trachomatis is the world's most prevalent cause of bacterial sexually transmitted infection and infectious blindness in endemic locations, primarily in Africa and the Middle East infecting approximately a hundred million people each year [1, 2]. Chlamydia trachomatis is a parasite that lives only inside cells. It goes
\end{abstract}


through a replicative developmental growth cycle inside the cells of its host, which leads to cell death [3]. According to the World Health Organization, 92 million new instances of Chlamydia trachomatis infection occur each year [4]. In the USA, it is estimated that over 3 million chlamydial infections occur each year among sexually active adolescents and adults [5, 6]. From 1993 to 2011, the number of chlamydial infections reported to the Centers for Disease Control and Prevention (CDC) increased from 178 to 453.4 cases per 100,000 people [7]. Human illnesses caused by Chlamydia trachomatis include cervicitis, salpingitis, acute urethral syndrome, endometritis, ectopic pregnancy, infertility, and pelvic inflammatory disease (PID) in women; conjunctivitis and pneumonia in neonates; and urethritis, proctitis, and epididymitis in males [8]. Traditional and orthodox treatment of some existing drugs is ineffective and unable to stop the process of a fasting-growing parasitic organelle inside the host cell called "Inclusion," which is poorly understood $[9,10]$. The development of novel potential therapies for the treatment of Chlamydia trachomatis represents an important means of extending life span and improving quality of life [11, 12]. Antimicrobial resistance has been listed by the World Health Organization (WHO) as one of the three most serious threats to human health and a severe problem in many parts of the world [13]. Chlamydia trachomatis a Gramnegative bacterium stands as proof of high-level resistance to most categories of antibiotics [14]. Infections caused by multidrug-resistant Chlamydia trachomatis are on the rise in hospitals, especially in the intensive care unit (ICU), and are linked to greater expenses, increased morbidity, and high fatality rates [15]. Increased patient contact with health care personnel, increased severity of illness, overuse of existing antimicrobial agents, underlying conditions, exposure to multiple invasive devices and procedures, and crowding of patients in a small specialized area are all factors that contribute to an increased risk of infection in intensive care unit patients [16]. As a result, finding new strong, safer, and less expensive Chlamydia trachomatis or bacterial inhibitors has become the greatest problem the human race has ever faced. For this reason, the development of new drugs able to fight Chlamydia trachomatis is still in great interest.

Previous studies on anti-Chlamydia trachomatis compounds have been published; one is on the synthesis of substituted ring-fused 2-pyridines and evaluation for the ability to attenuate Chlamydia trachomatis infectivity [17]. In 2014, Abdelsayed and his colleagues design and synthesize a 3-isoxazolidone derivative and also evaluate the paths by which these new compounds affect Chlamydia trachomatis serovar L2 development in HeLa cells, in the presence or absence of exogenously added iron
[1]. Edache and his co-workers conducted quantitative structure-activity relationship (2D-QSAR), comparative molecular field analysis (CoMFA), and molecular dynamics simulations on novel thiazoline 2-pyridone amide derivatives [2]. In recent years, the use of molecular modeling has produced very impressive results in the drug discovery process [18].

In this place, we report the molecular modeling of salicylidene acylhydrazides derivatives to continue our ongoing research on Chlamydia trachomatis inhibitor molecular modeling. The docking simulation, molecular dynamics simulations, and ADMET filtering were applied to detect new potential candidates for Chlamydia trachomatis treatment.

\section{Methods}

In the present study, we have selected 58 salicylidene acylhydrazides derivatives from the PubChem database (www.ncbi.nlm.nih.gov/pubchem) with accession number AID 473049/473050 that have been already validated to have antimicrobial activity. All compounds were tested using the same experimental procedure, and a wide range of Chlamydia trachomatis inhibition activities were covered. Structures of the selected prevailing forms were optimized with the semiempirical PM3 method using the Spartan'14 software (www.wavefun.com) (Table 1). The optimized structures were saved for further analysis.

\section{Virtual screening using multiple molecular docking tools}

The strength of association or binding affinity between two molecules can be predicted by molecular docking techniques [19]. Molecular docking simulations were calculated from three different algorithms; therefore, it is assumed that the value represents a real condition. We chose 58 phytochemical substances that have been considered to have potential antibacterial activity for this study. The three-dimensional crystal structure of the IncA soluble domain was retrieved from RCSB (www.rcsb.org/ $\mathrm{pdb}$ ) protein data bank (PDB Code: 6e7e). The whole structure of the receptors was targeted for our molecular docking study except for heteroatoms that were detected from the receptors. Primary docking analysis was performed using iGemdock [20], which uses empirical scoring function and Generic Evolutionary Method for molecular docking. It comes with a graphical user interface that detects pharmacological interactions and does virtual screening. The following parameters for docking have been chosen: population size $=200$, number of generations $=70$, and number of solutions $=3$. To further increase the docking accuracy, by using a more complex scoring function, Molegro Virtual Docker (MVD) was used [21]. The imported structures must be properly prepared, that is, the atom connectivity and bond orders are correct, and partial atomic charges are assigned. PDB files often have the poor or missing assignment of explicit hydrogen, and the PDB file format cannot accommodate bond 
Table 1 PubChem_CID number and corresponding activity $\mathrm{plC}_{50}$ of salicylidene acylhydrazides derivatives

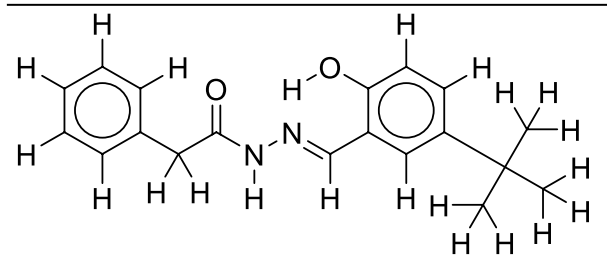

1: PUBCHEM_CID 135804387; $\mathrm{pIC}_{50}=8.000$<smiles>C=CC(=O)/N=N/C=C\c1ccccc1</smiles>

2: PUBCHEM_CID 135504477; $\mathrm{pIC}_{50}=7.824$<smiles>O=C(N/N=C/c1ccccc1)c1cccnc1</smiles>

3: PUBCHEM_CID 135480441; $\mathrm{pIC}_{50}=7.367$

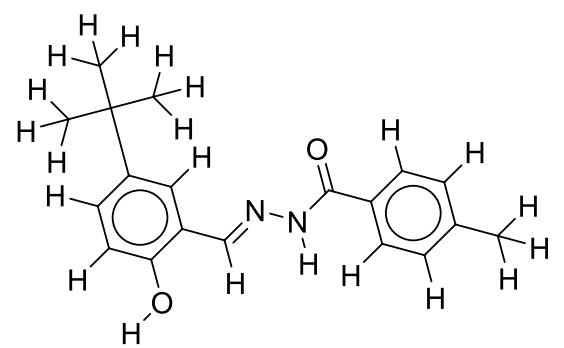

4: PUBCHEM_CID $136167947 ; \mathrm{pIC}_{50}=7.699$<smiles>O=C(N/N=C/c1ccccc1)c1ccccc1</smiles>

5: PUBCHEM_CID 136167948; $\mathrm{pIC}_{50}=7.721$<smiles>[1H]C([2H])([2H])Oc1ccc(Br)c(/C=N/NC(=O)c2snnc2C)c1O</smiles>

6: PUBCHEM_CID 136167949; $\mathrm{pIC}_{50}=7.469$<smiles>O=C(COc1cccc(F)c1)N/N=C/c1cc(I)cc(I)c1O</smiles>

13: PUBCHEM_CID 136167956; $\mathrm{pIC}_{50}=7.678$<smiles>O=C(N/N=C/c1ccc(Cl)cc1)c1cc(I)c(Cl)cc1I</smiles>

14: PUBCHEM_CID 136167957; $\mathrm{pIC}_{50}=7.638$<smiles>[H]/C=N\N(C)C(=O)c1ccc(/C=N\N)c(OC([2H])[2H])c1OC[CH]</smiles>

15: PUBCHEM_CID 135615180; $\mathrm{pIC}_{50}=7.699$<smiles>[H]/C=C\N/N=C/c1ccccc1OC=O</smiles>

16: PUBCHEM_CID 135472433; $\mathrm{pIC}_{50}=7.721$<smiles>CN(/N=C\c1ccc(O)c(O)c1O)C(=O)C/C=C\c1ccc(O)cc1</smiles>

17: PUBCHEM_CID 136167958; $\mathrm{pIC}_{50}=7.602$<smiles>CN(/N=C\c1ccccc1O)C(=O)c1sc2ccccc2c1Cl</smiles>

18: PUBCHEM_CID 136167959; $\mathrm{pIC}_{50}=7.357$ 
Table 1 (continued)

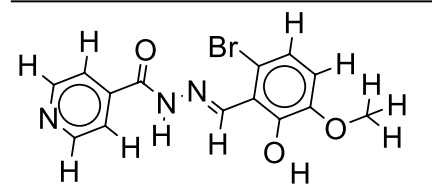

7: PUBCHEM_CID 136167950; $\mathrm{pIC}_{50}=7.569$<smiles>[H]/C=C\Oc1c(O)ccc(Br)c1/C=N/NC(=O)C([2H])C#N</smiles>

8: PUBCHEM_CID 136167951; $\mathrm{pIC}_{50}=7.699$<smiles>[2H]c1cc(Cl)cc(O)c1/C=N\NC(=O)c1cc(O[CH2])ccc1Br</smiles>

9: PUBCHEM_CID 136167952; $\mathrm{pIC}_{50}=7.509$<smiles>O=C(N/N=C\c1ccccc1)c1ccc(Br)cc1</smiles>

10: PUBCHEM_CID 136167953; $\mathrm{pIC}_{50}=7.538$

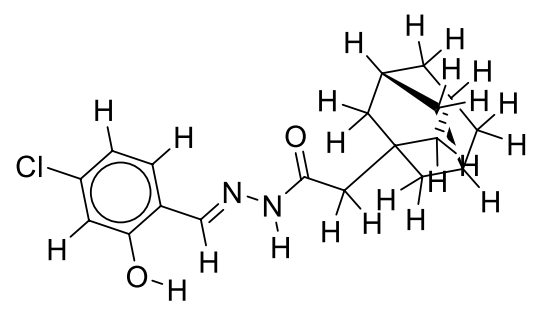

11: PUBCHEM_CID 136167954; $\mathrm{pIC}_{50}=7.602$

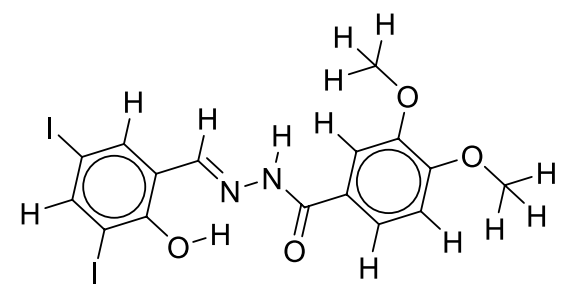

12: PUBCHEM_CID 136167955; pIC50=7.529<smiles>NNC(=O)C(=O)N/N=C/c1c(O)cc(O)cc1O</smiles>

19: PUBCHEM_CID 136167960; $\mathrm{pIC}_{50}=7.585$<smiles>O=C(N/N=C\c1ccccc1)c1ccccc1</smiles>

20: PUBCHEM_CID 136167961; $\mathrm{pIC}_{50}=7.523$<smiles>[2H]c1cccc(OCC(=O)N/N=C/c2ccccc2)c1O</smiles>

21: PUBCHEM_CID 136167962; $\mathrm{pIC}_{50}=7.602$<smiles></smiles>

22: PUBCHEM_CID 136167963; $\mathrm{pIC}_{50}=7.770$<smiles>[H]/C=C\C(=O)N/N=C/c1cccc(Br)c1O</smiles>

23: PUBCHEM_CID 135501372; $\mathrm{pIC}_{50}=7.699$

24: PUBCHEM_CID 135567720; $\mathrm{pIC}_{50}=7.260$ 
Table 1 (continued)<smiles>[H]/C=C\c1c(O)ccc(/C=N/N(C)C(=O)c2ccc(OC)c(Br)c2)c1/C=C\C([2H])([2H])C</smiles>

25: PUBCHEM CID 136167964; $\mathrm{pIC}_{50}=7.745$<smiles></smiles>

26: PUBCHEM_CID 136167965; $\mathrm{pIC}_{50}=7.469$

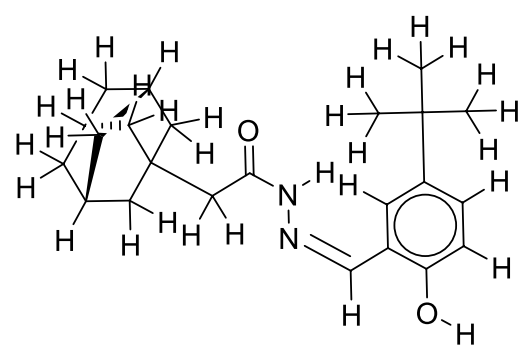

27: PUBCHEM_CID 136167966; $\mathrm{pIC}_{50}=7.770$

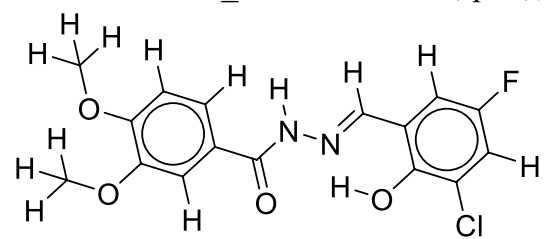

28: PUBCHEM_CID 136167967; $\mathrm{pIC}_{50}=8.000$<smiles>[H]/C=C\C(=O)N/N=C/c1[Z]([H])ccc2ccc(F)cc12</smiles>

29: PUBCHEM_CID 136167968; $\mathrm{pIC}_{50}=7.824$<smiles>O=C(N/N=C/c1ccc(F)cc1Cl)c1cc(Cl)c(Cl)cc1Cl</smiles>

30: PUBCHEM_CID 136167969; $\mathrm{pIC}_{50}=7.959$<smiles>[H]/C=C\N/N=C/c1ccc([N+](=O)[O-])cc1OC</smiles>

40: PUBCHEM_CID 135589440; $\mathrm{pIC}_{50}=7.553$<smiles>[H]/C=C\NC(=O)C([2H])C#N</smiles>

41: PUBCHEM_CID 135439717; $\mathrm{pIC}_{50}=7.569$<smiles>[H][Z]([H])([H])Oc1ccc(Br)c(C(=O)N/N=C\c2c([2H])c([N+](=O)[O-])cc([N+](=O)[O-])c2O)c1</smiles>

42: PUBCHEM_CID 136167977; $\mathrm{pIC}_{50}=7.638$<smiles>O=C(N/N=C\c1ccccc1)c1ccc(Br)cc1</smiles>

43: PUBCHEM_CID 135628628; $\mathrm{pIC}_{50}=7.721$

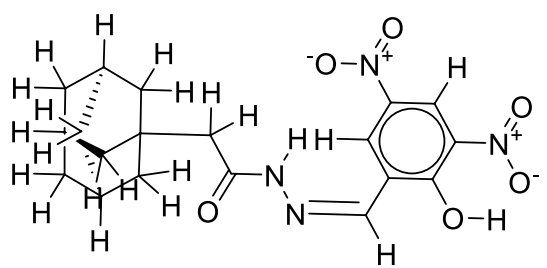

44: PUBCHEM_CID 136167978; $\mathrm{pIC}_{50}=8.222$

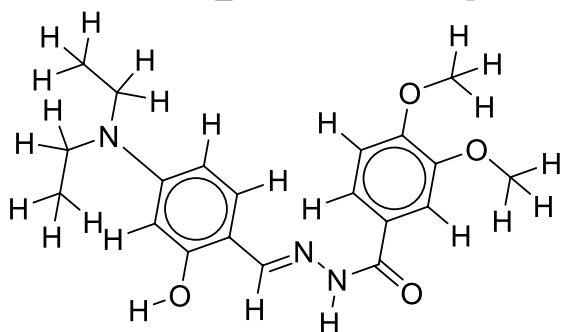

45: PUBCHEM_CID 135518293; $\mathrm{pIC}_{50}=7.357$ 
Table 1 (continued)

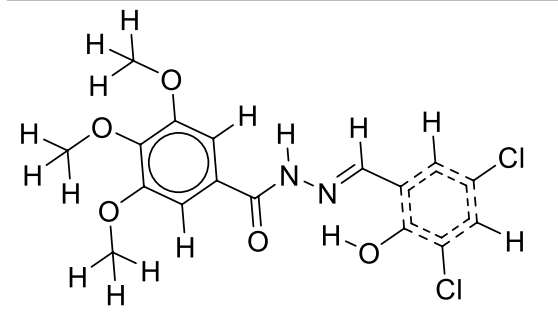

31: PUBCHEM_CID 135643056; $\mathrm{pIC}_{50}=7.745$<smiles>O=C(N/N=C/c1cccc(Cl)c1[OH2+])c1ccccc1Cl</smiles>

32: PUBCHEM_CID 135495624; $\mathrm{pIC}_{50}=7.745$

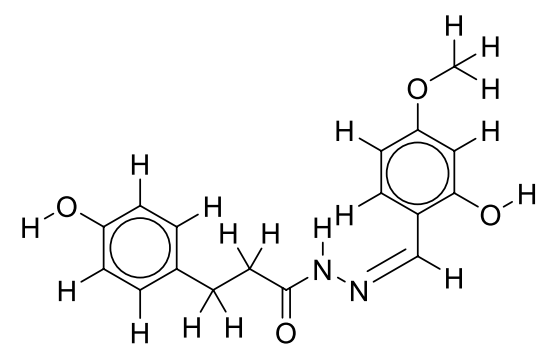

33: PUBCHEM_CID 136167970; $\mathrm{pIC}_{50}=7.921$

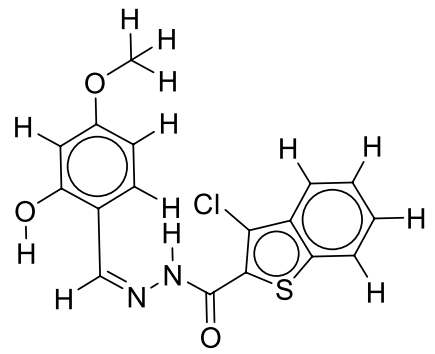

34: PUBCHEM_CID 136167971; $\mathrm{pIC}_{50}=7.824$<smiles></smiles>

35: PUBCHEM_CID 136167972; $\mathrm{pIC}_{50}=7.886$<smiles>[H]/C=C\c1ccc(/C=N/NC(=O)C(C)Oc2ccc(F)cc2)c(O)c1</smiles>

46: PUBCHEM_CID 136142892; $\mathrm{pIC}_{50}=7.456$
47: PUBCHEM_CID 136167979; pIC =7.469

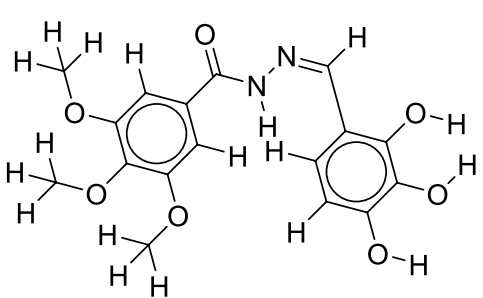

48: PUBCHEM_CID 136167980; $\mathrm{pIC}_{50}=7.509$<smiles>O=C(N/N=C/c1cccc([18OH])c1[N+](=O)[O-])c1ccccc1</smiles>

49: PUBCHEM_CID 136167981; $\mathrm{pIC}_{50}=7.658$<smiles>[2H]C(C)=CC(=O)N/N=C/c1cccc(OC)c1O</smiles>

50: PUBCHEM_CID 136167982; $\mathrm{pIC}_{50}=7.745$

order information. The utilities included in MVD were used to do all necessary valency tests and $\mathrm{H}$-atom additions. The binding location is the area where the docking procedure will look for promising poses. The docking simulation results were then validated through AutoDock Vina [22] (PyRx software) with the following setup: exhaustiveness $=8$; center_ $\mathrm{x}=-2.3621$; center_y $=17.7247$; center_z $=36.6066$; size $\_x=71.1413702774$; size_y $=32.6226404202$; size_z $=50.6705288601$, and the interaction of all the docking approach was visualized through Discovery studio software. 
Table 1 (continued)

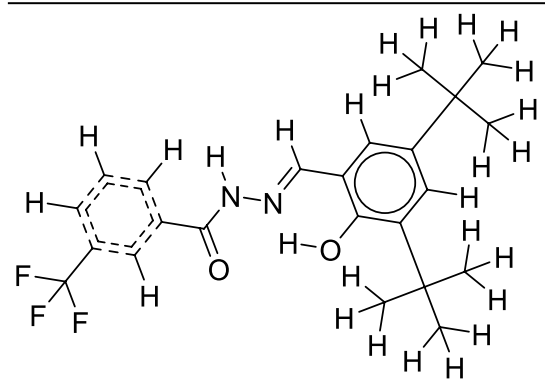

36: PUBCHEM_CID 136167973; $\mathrm{pIC}_{50}=8.222$

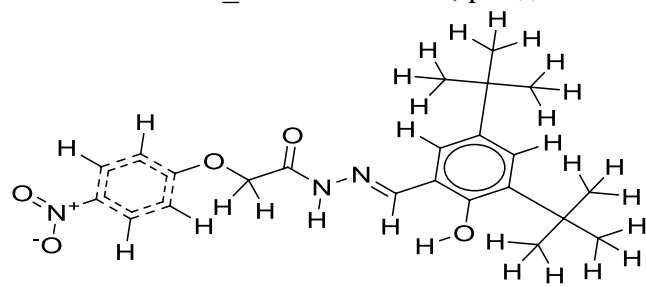

37: PUBCHEM_CID 136167974; $\mathrm{pIC}_{50}=7.921$

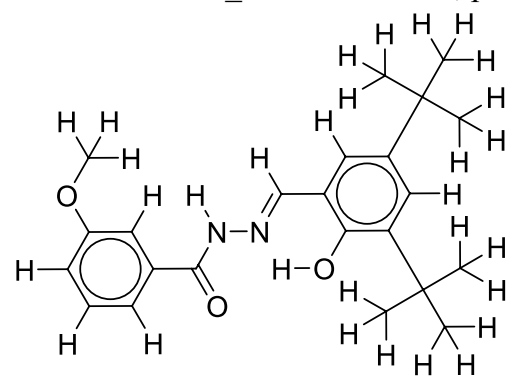

38: PUBCHEM_CID 136167975; $\mathrm{pIC}_{50}=7.854$<smiles></smiles>

39: PUBCHEM_CID 136167976; $\mathrm{pIC}_{50}=7.409$<smiles>O=C(N/N=C/c1ccccc1O)c1cccnc1</smiles>

55: PUBCHEM_CID 136167986; $\mathrm{pIC}_{50}=7.569$

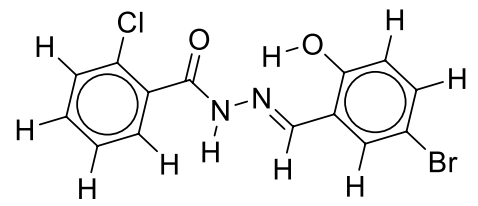

56: PUBCHEM_CID 135521406; $\mathrm{pIC}_{50}=7.959$

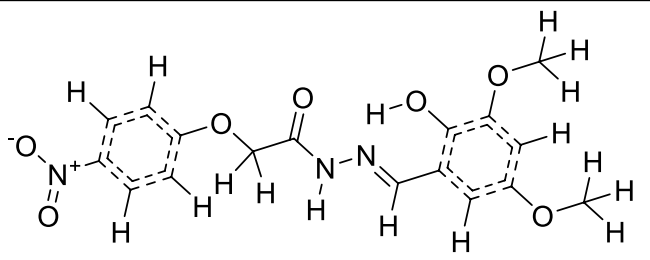

51: PUBCHEM_CID 136167983; $\mathrm{pIC}_{50}=7.745$<smiles>[1H]C(=O)C(=O)N/N=C/c1cc(Br)c([2H])c(O)c1O</smiles>

52: PUBCHEM_CID 135815951; $\mathrm{pIC}_{50}=8.000$<smiles>[H]/C=C\c1cccc(OC[CH])c1O</smiles>

53: PUBCHEM_CID 136167984; $\mathrm{pIC}_{50}=7.699$

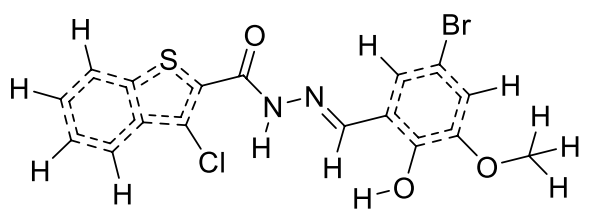

54: PUBCHEM_CID 136167985; $\mathrm{pIC}_{50}=7.638$

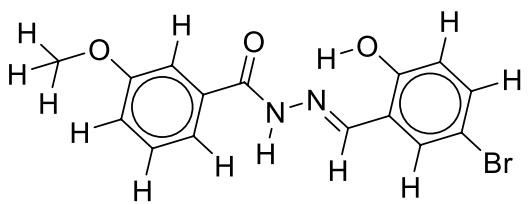

57: PUBCHEM_CID 135615174; $\mathrm{pIC}_{50}=7.658$

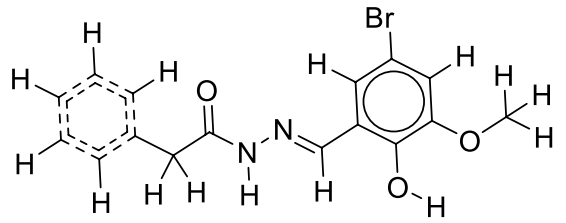

58: PUBCHEM_CID 135536260; $\mathrm{pIC}_{50}=8.046$ 


\section{ADMET, drug-likeness evaluation}

Candidates for drugs should have positive ADME qualities and, ideally, be non-toxic. Using the DataWarrior software, the developed compounds were tested for their ADME profile, which included drug-likeness, partition coefficient, solubility, and several other metrics. In addition, the toxicity of the chosen drug was predicted.

\section{Molecular dynamic (MD) simulation}

The chosen complex was then simulated for 1 ns with VMD-NAMD software [23, 24]. To construct receptor molecular topology and configuration files, the Charmmgui Web site was utilized. By adding $0.15 \mathrm{M} \mathrm{KCl}$ to the simulated system, the system was neutralized. TIP3PBOX, a water molecules box, was then submerged in the neutralized system. Each system was equilibrated with NVT (constant number of particles, volume, and temperature) as well as NPT (constant number of particles, pressure, and temperature) before the production phase to guarantee an even distribution of solvent and ions surrounding the protein-ligand complex.

\section{Results}

\section{Docking evaluations}

Tables 2 and 3 reveal the numerical value of the total energy, van der Waals, hydrogen bond, and electrostatic of the standard drugs and the 58 salicylidene acylhydrazides derivatives with iGemDock v2.1 software. The docking interactions of the standard drugs and the best interacting ligand are reflected in Figs. 1 and 2.

With Molegro Virtual Docker (MVD) and PyRx software, all the standard drugs and ligands were docked with the protein structure and the best-docked molecules were listed depending on their MolDock score, Rerank score, hydrogen bond, and binding affinity as given in Tables 4 and 5. Figures 3 and 4 show detailed interaction of the standard drugs and the best four ligands with the MVD program, while Figs. 5 and 6 give in detail the docking pose of the reference or standard drugs and the four best ligands with PyRx software, respectively.

Table 2 The results of the reference drugs with iGemDock v2.1

\begin{tabular}{lllll}
\hline SD & Total energy & VDW & HBond & Elec \\
\hline Ampicillin & -92.5875 & -64.7854 & -27.8021 & 0 \\
Oxytetracycline & -90.744 & -62.8534 & -27.8906 & 0 \\
Chlortetracycline & -90.6709 & -54.49 & -36.1809 & 0 \\
Ceftriaxone & -82.7819 & -55.1418 & -25.9849 & -1.65517 \\
\hline
\end{tabular}

$\mathrm{SD}$, standard drugs

\section{Pharmacokinetic evaluation}

Lipinski's rule of 5 and Veber's rule of 2 of both the standard drugs and the selected compounds are reflected in Table 6. Table 7 shows the lipophilicity of the selected drugs, while Table 8 presents the toxicity risk factors of the standard drugs and the selected compounds.

\section{Golden triangle and MD simulations}

Figure $8 \mathrm{~A}-\mathrm{C}$ shows the variation in kinetic energy, total energy, potential energy versus time in 1-ns MD simulations, while Fig. 8D shows the binding interaction of the simulated complex.

\section{Discussion}

Docking screening of compounds with iGemdock software Four anti-Chlamydia trachomatis drugs-ampicillin, oxytetracycline, chlortetracycline, and ceftriaxone, were used as a control for the following study. iGemdock calculated the total energy, van der Waals energy, electrostatic, and hydrogen bond of the four standard drugs when docking them into the enzymes. K-means and hierarchal clustering approaches are used by iGemdock's post-analysis tools. Table 2 shows the summary of docking results, and detailed interactions with the enzyme are shown in Fig. 1. Binding energies of the receptor-ligand interactions are very important to report how fit the drug binds to the target macromolecule. It can be calculated that according to iGemdock ampicillin is the best binding receptor because of its total energy of $-92.5875 \mathrm{kcal} /$ mol. A higher fitness score suggests better docking interaction between protein and ligand and will be acceptable of the compound as a drug.

The total energy of compounds 4, 38, 43, 44, and 48 was found to be $-78.3402,-76.561,-78.9421,-87.3827$, and $-77.9572 \mathrm{kcal} / \mathrm{mol}$, respectively (Table 3 ). From the results, a good number of standards (Table 2) displayed activity comparable to those selected compounds. Compound 44 has the best score and the most outstanding inhibitory activity from the selected ligands, amino acids involved in its van der Waals interaction with receptor molecules are His249, His250, His253, Ser154, Thr238, Arg245, and Lys246, while those in hydrophobic interactions include Ile241 and Ala242 and one pi-donor hydrogen bond with His249 (Fig. 2).

\section{Docking screening of compounds with Molegro Virtual Docker (MVD)}

The standards docked drugs were listed depending on their MolDock score as given in Table 4, and the nature of interaction with the protein structure is shown in Fig. 3. The best pose of the docked molecules was analyzed based on the lowest MolDock score. Docking results showed that ceftriaxone was best docked with the 
Table 3 The results of the 58 salicylidene acylhydrazides derivatives with iGemDock v2.1

\begin{tabular}{|c|c|c|c|c|c|c|}
\hline No & Ligand & Total energy & VDW & HBond & Elec & AverConPair \\
\hline 1 & 6e7e-44-0.pdb & -87.3827 & -87.3827 & 0 & 0 & 18.4138 \\
\hline 2 & 6e7e-43-0.pdb & -78.9421 & -78.9421 & 0 & 0 & 19.04 \\
\hline 3 & 6e7e-4-2.pdb & -78.3402 & -78.3402 & 0 & 0 & 20.3478 \\
\hline 4 & 6e7e-48-1.pdb & -77.9572 & -77.9572 & 0 & 0 & 19.2308 \\
\hline 5 & 6e7e-38-1.pdb & -76.561 & -76.561 & 0 & 0 & 17.25 \\
\hline 6 & 6e7e-54-0.pdb & -75.6408 & -75.6408 & 0 & 0 & 18.92 \\
\hline 7 & 6e7e-40-1.pdb & -74.12 & -74.12 & 0 & 0 & 19.2609 \\
\hline 8 & 6e7e-29-0.pdb & -73.4891 & -73.4891 & 0 & 0 & 20 \\
\hline 9 & 6e7e-45-1.pdb & -73.338 & -73.338 & 0 & 0 & 18.8889 \\
\hline 10 & $6 e 7 e-45-1 . p d b$ & -73.338 & -73.338 & 0 & 0 & 18.8889 \\
\hline 11 & 6e7e-5-2.pdb & -72.2371 & -72.2371 & 0 & 0 & 19.0455 \\
\hline 12 & 6e7e-14-1.pdb & -71.4777 & -71.4777 & 0 & 0 & 20.3636 \\
\hline 13 & 6e7e-6-1.pdb & -71.3965 & -71.3965 & 0 & 0 & 19.7143 \\
\hline 14 & 6e7e-39-0.pdb & -71.2635 & -71.2635 & 0 & 0 & 17.0769 \\
\hline 15 & $6 e 7 e-46-1 . p d b$ & -71.1864 & -71.1864 & 0 & 0 & 16.4231 \\
\hline 16 & 6e7e-57-1.pdb & -70.8057 & -70.8057 & 0 & 0 & 20.1905 \\
\hline 17 & 6e7e-13-0.pdb & -70.6842 & -70.6842 & 0 & 0 & 19.4348 \\
\hline 18 & 6e7e-1-2.pdb & -70.1351 & -70.1351 & 0 & 0 & 18.2174 \\
\hline 19 & 6e7e-34-0.pdb & -70.0374 & -70.0374 & 0 & 0 & 18 \\
\hline 20 & 6e7e-30-2.pdb & -69.8395 & -69.8395 & 0 & 0 & 20.4091 \\
\hline 21 & 6e7e-12-0.pdb & -69.6612 & -69.6612 & 0 & 0 & 18.7083 \\
\hline 22 & 6e7e-47-0.pdb & -69.4781 & -69.4781 & 0 & 0 & 16.88 \\
\hline 23 & 6e7e-28-1.pdb & -69.0599 & -69.0599 & 0 & 0 & 17.4167 \\
\hline 24 & 6e7e-41-1.pdb & -68.9204 & -68.9204 & 0 & 0 & 20.05 \\
\hline 25 & 6e7e-22-1.pdb & -68.7563 & -68.7563 & 0 & 0 & 19.5238 \\
\hline 26 & 6e7e-16-0.pdb & -67.8887 & -67.8887 & 0 & 0 & 18.5652 \\
\hline 27 & 6e7e-17-1.pdb & -67.8206 & -67.8206 & 0 & 0 & 16.3478 \\
\hline 28 & 6e7e-33-0.pdb & -67.7813 & -67.7813 & 0 & 0 & 17.1739 \\
\hline 29 & 6e7e-23-1.pdb & -66.7408 & -66.7408 & 0 & 0 & 20.4737 \\
\hline 30 & 6e7e-57-0.pdb & -66.5272 & -66.5272 & 0 & 0 & 17.8095 \\
\hline 31 & 6e7e-10-0.pdb & -64.5692 & -64.5692 & 0 & 0 & 20.15 \\
\hline 32 & 6e7e-26-2.pdb & -63.4082 & -63.4082 & 0 & 0 & 18.2609 \\
\hline 33 & 6e7e-35-0.pdb & -61.2651 & -61.2651 & 0 & 0 & 21.6471 \\
\hline 34 & $6 e 7 e-52-2 . p d b$ & -61.1252 & -61.1252 & 0 & 0 & 19.3333 \\
\hline 35 & 6e7e-19-0.pdb & -57.6773 & -57.6773 & 0 & 0 & 21.4706 \\
\hline 36 & 6e7e-8-0.pdb & -57.1784 & -57.1784 & 0 & 0 & 21.3333 \\
\hline 37 & 6e7e-8-0.pdb & -57.1784 & -57.1784 & 0 & 0 & 21.3333 \\
\hline 38 & 6e7e-24-1.pdb & -56.8114 & -56.8114 & 0 & 0 & 23.5625 \\
\hline 39 & 6e7e-37-0.pdb & -38.9493 & -38.9493 & 0 & 0 & 13.2258 \\
\hline 40 & 6e7e-58-0.pdb & -31.2029 & -31.2029 & 0 & 0 & 13.3182 \\
\hline 41 & 6e7e-21-0.pdb & -9.41303 & -9.41303 & 0 & 0 & 12.375 \\
\hline 42 & 6e7e-15-0.pdb & -1.74972 & -1.74972 & 0 & 0 & 10 \\
\hline 43 & 6e7e-50-0.pdb & 0.890899 & 0.890899 & 0 & 0 & 14.0417 \\
\hline 44 & 6e7e-18-0.pdb & 11.5326 & 11.5326 & 0 & 0 & 17.625 \\
\hline 45 & 6e7e-27-0.pdb & 18.0226 & 18.0226 & 0 & 0 & 18.2222 \\
\hline 46 & 6e7e-31-0.pdb & 29.5633 & 29.5633 & 0 & 0 & 12.8846 \\
\hline 47 & 6e7e-2-0.pdb & 30.294 & 30.294 & 0 & 0 & 17.2 \\
\hline 48 & 6e7e-9-0.pdb & 56.4153 & 56.4153 & 0 & 0 & 16.5455 \\
\hline 49 & 6e7e-9-0.pdb & 56.4153 & 56.4153 & 0 & 0 & 16.5455 \\
\hline
\end{tabular}


Table 3 (continued)

\begin{tabular}{llccccc}
\hline No & Ligand & Total energy & VDW & HBond & Elec & AverConPair \\
\hline 50 & 6e7e-51-0.pdb & 70.1743 & 70.1743 & 0 & 0 & 16.1481 \\
51 & 6e7e-42-0.pdb & 91.6956 & 91.6956 & 0 & 0 & 13.8889 \\
52 & 6e7e-25-0.pdb & 98.3126 & 98.3126 & 0 & 0 & 15.44 \\
53 & 6e7e-11-0.pdb & 143.872 & 143.872 & 0 & 0 & 22.2917 \\
54 & 6e7e-53-0.pdb & 144.199 & 144.199 & 0 & 0 & 21.4583 \\
55 & 6e7e-36-0.pdb & 181.578 & 181.578 & 0 & 0 & 16.2 \\
56 & 6e7e-20-0.pdb & 195.275 & 195.275 & 0 & 0 & 36.8696 \\
\hline
\end{tabular}

protein structure. Ceftriaxone with the protein was found to be the most active with the best MolDock value as $(-124.659)$ as compared to all the other poses as shown in Table 4. The result showed that ceftriaxone perfectly binds with the active regions of the target protein by forming hydrophobic interactions with Gln114, Lys115, and Phe108 as shown in Fig. 3. Oxytetracycline makes other side interactions (unfavorable bump and unfavorable donor-donor) with Gly144, Phe145, and Ser111 amino residue, as such can lead to side effects.

Accordingly, all the 58 salicylidene acylhydrazides derivatives were docked into the binding pocket of the protein. The MolDock score, rerank score, and hydrogen bond values of the five most active compounds from the 58 datasets are provided in Table 5 . It was observed (Table 4) that ceftriaxone, in particular, showed a superior binding affinity with a MolDock score of -124.659 , in comparison with compounds $16,23,32,44$, and 51 with a MolDock score of $-102.325,-105.42,-103.832,-101.187$, and -104.935 , respectively. Hydrogen bond, electrostatic, and hydrophobic interactions of compounds 16, 23, 32, and 51 with the protein are illustrated in Fig. 4. Likewise, docking pose analysis of four best-performing derivatives (compounds 16, 23, 32, and 51) showed the similarity of binding mode compared to the standard drugs. The similarity is observed in the urea moiety of the compounds, which is with Lys160, Asn161, Ser162, Glu158, Met166, Glu248, His252, His251, His249, Thr163, Arg245, and Asp157, respectively. The MolDock score of compounds $16,23,32,44$, and 51 is far better than the rest of the standard drugs (ampicillin, oxytetracycline, and chlortetracycline).

\section{Docking screening of compounds with AutoDock Vina (PyRx software)}

Based on AutoDock Vina (Table 5), out of 58 compounds used in the present study, compounds 36, 37, and 39 exhibited the lowest binding affinity with the enzyme $(-6.9 \mathrm{kcal} / \mathrm{mol})$ active sites, followed by compounds 44 and $50(-6.8 \mathrm{kcal} / \mathrm{mol})$ and compounds 11 and 20
(-6.7 kcal/mol), respectively. Compounds 36,37 , and 39 display the highest docking scores when compared with the standard drugs (Table 4); furthermore, chlortetracycline (standard drug) showed the highest binding energy of $-6.8 \mathrm{kcal} / \mathrm{mol}$ and exhibited two binding interactions;:van der Waals interaction with His249, His252, Thr163, Glu248, and Tyr159 and four hydrogenbonding interactions with Glu158, Arg245, Asp157, and Asn161 (Fig. 5). Ampicillin, oxytetracycline, and ceftriaxone showed binding affinities of $-6.0,-6.5$, and $-6.1 \mathrm{kcal} / \mathrm{mol}$, respectively. These compounds were bound at the van der Waals, conventional and carbonhydrogen bond, ampicillin has one hydrophobic interaction with Lys235, and ceftriaxone has unfavorable donor-donor with Arg146 as shown in Fig. 5.

The selected compounds $(36,37,39$, and 44) all have a higher binding affinity than the standard drugs except compounds 44 and 50 that have their binding energy equal to chlortetracycline of the standard drug. Compounds 36 and 39 were found to have the highest binding affinity as such are more compatible with the receptor than compounds 37 and 44 with unfavorable bumps (Fig. 6). As illustrated in Fig. 6, there are a variety of interactions between these chemicals, and the target protein revealed that compound 36 interacts with one hydrogen bond with Glu215 and one carbon-hydrogen bond with Phe191. In addition to the binding interactions of compound 36 are hydrophobic (Ile219, Phe191, and Pro194), van der Waals (Thr218, Leu195, and Glu198), and Halogen (Glu188) interaction between amino acid residues, respectively. Compound 39 has three conventional hydrogen bonds with His204, Arg200, and Glu197, one carbon-hydrogen bond with Phe124, and hydrophobic interactions with Arg201, His204, His204, Arg200, and Phe124, respectively.

It was concluded from the docking simulation that compound 36 and compound 39 were strongly bonded through van der Waals, hydrophobic, and conventional 


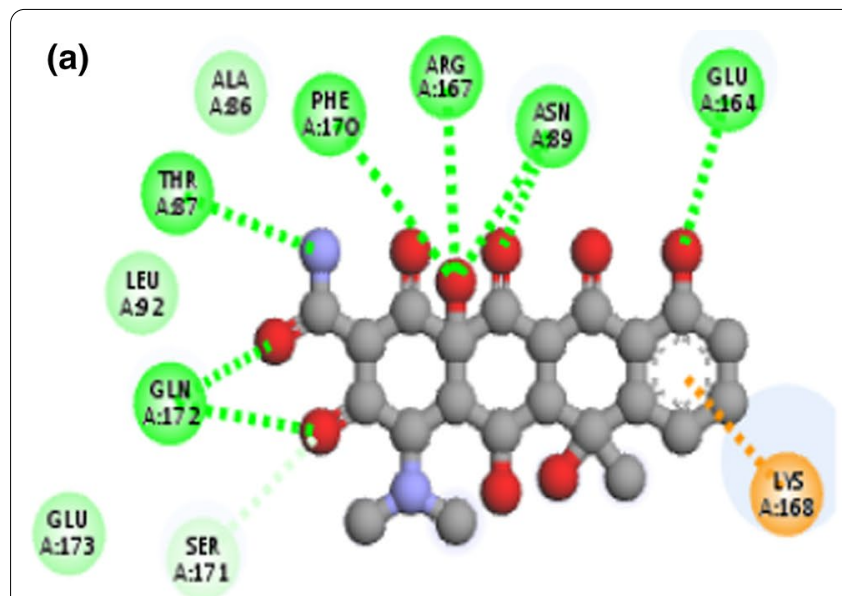

Interactions

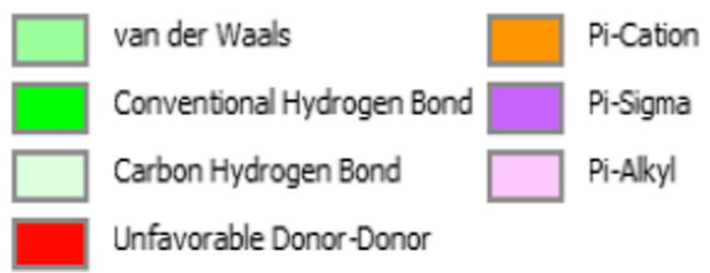

(c)

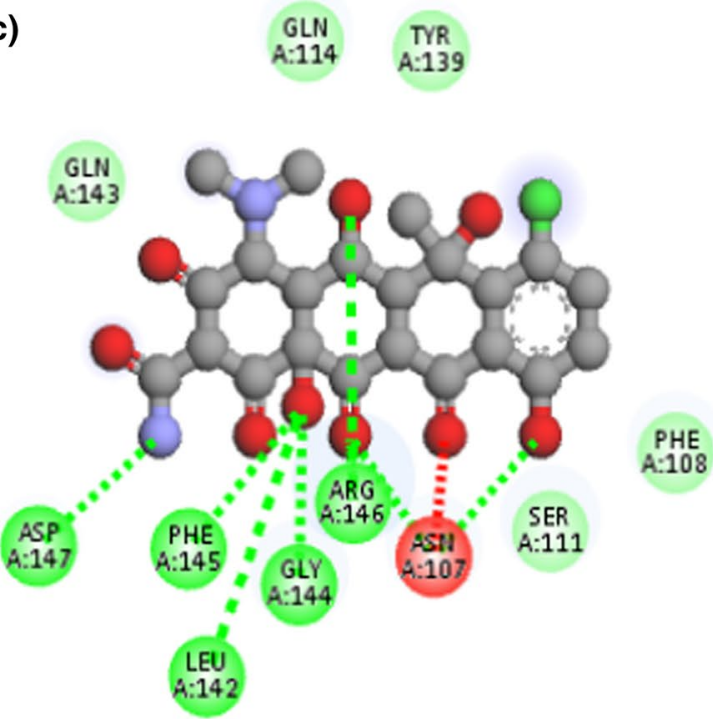

Interactions

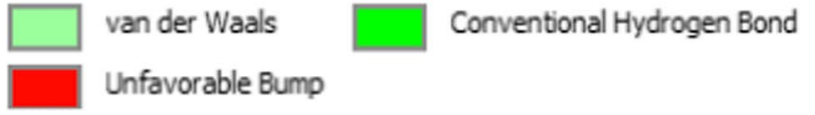

(b)

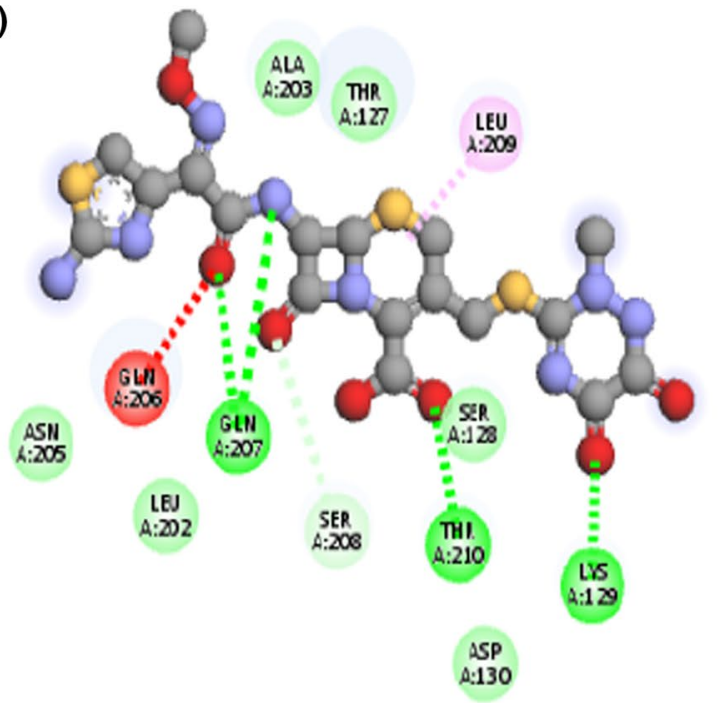

Interactions

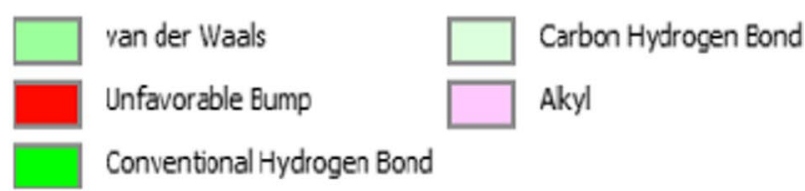

(d)

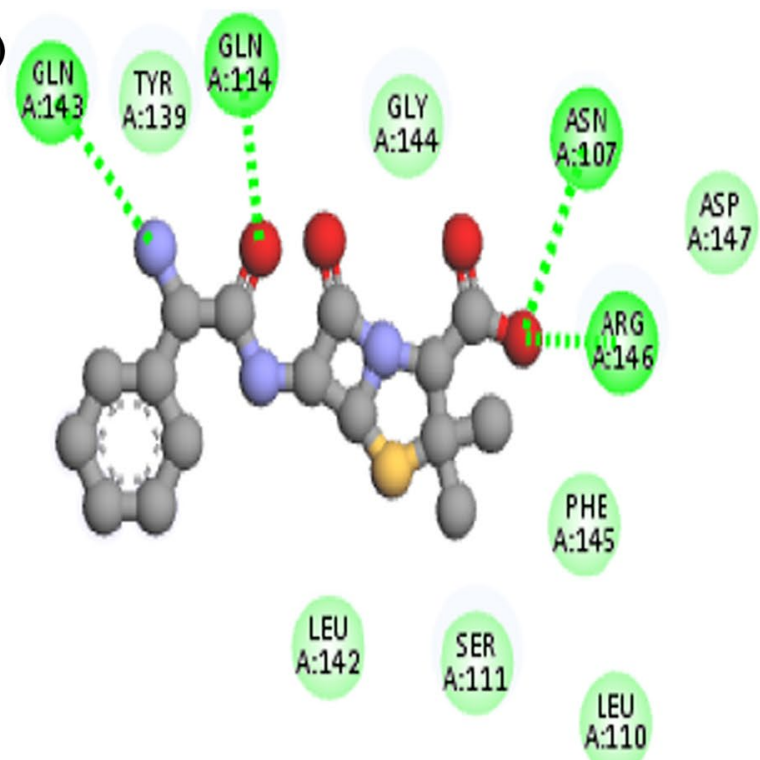

\section{Interactions}

van der Waals

Conventional Hydrogen Bond

Fig. 1 Interactions of the reference drugs: (A) ampicillin, (B) oxytetracycline, (C) chlortetracycline, and (D) ceftriaxone with the crystal structure of IncA soluble domain 


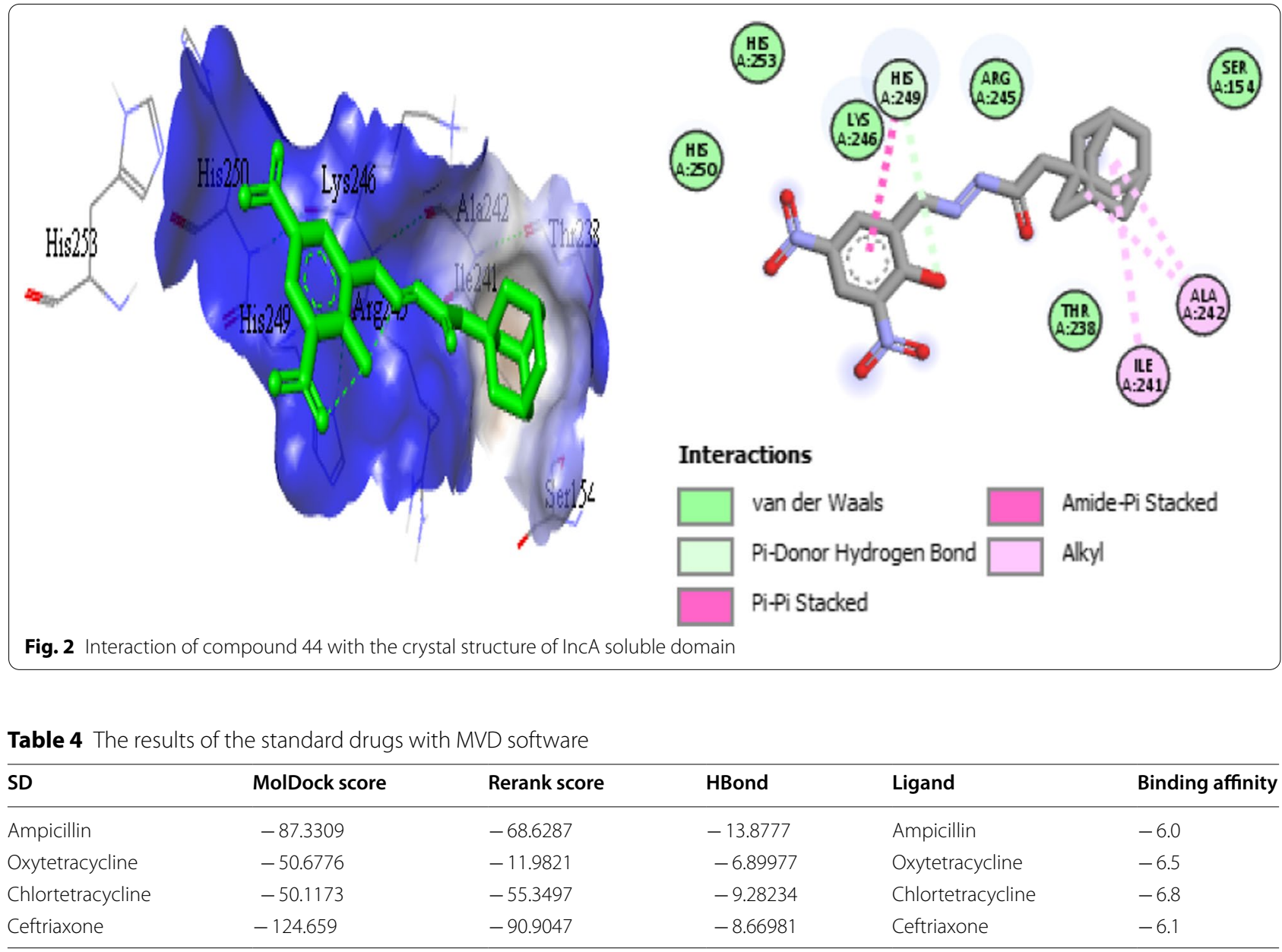

SD, standard drugs

hydrogen bond interactions and stabilized into the active site of the target protein.

\section{Oral bioavailability analysis of the selected compounds and standards}

These findings prompted us to evaluate the physicochemical properties of our selected lead compounds from the docking tools, one from iGemDock (compound 44), five from MVD (compounds 16, 23, 32, 44, and 51), and five from AutoDock Vina with PyRx (compounds $36,37,39,44$, and 50 ), respectively (Table 6 ), to identify compounds with optimal oral absorption properties and to guide future structural modifications to improve ADMET properties. The oral bioavailability analysis of selected compounds was predicted using DataWarrior v5.5.0 and is presented in Table 6; following Lipinski's rule of five [25] and Veber's rules of two [26], any compound violating more than one of these rules could have problems related to its bioavailability.
From the table (Table 6), all the compounds can easily pass through the cell membrane since their molecular weight is less than $500 \mathrm{Da}$, except chlortetracycline that has a molecular weight of more than $500 \mathrm{Da}$. If the size increases, it will create barriers such as the prevention of passive diffusion through the tight aliphatic side chains of the bilayer membrane [27]. According to the Lipinski rule, cLogP should be less than or equal to 5 , all the selected compounds have positive cLogP (affinity for lipids), so they have a good permeability through a biological membrane. Compound 36 is more than the threshold value of 5 , while the standard drugs have a negative value of cLogP, which means they are hydrophilic (strong affinity for water) [28]. A drug molecule is expected to be in an aqueous solubility, range of -1 to -5 [29], and the cLogS values of all the selected compounds and standards fall within the range, indicating that the compounds have good absorption and distribution potential except compound 36 with cLogS value of -6.523 . The number of hydrogen bond donors 
Table 5 The MolDock scores and AutoDock Vina binding affinity of the docked compounds

\begin{tabular}{|c|c|c|c|c|c|c|}
\hline Positions & Ligand & MolDock score & Rerank score & HBond & $\begin{array}{l}\text { AutoDock vina: } \\
\text { ligand }\end{array}$ & Binding affinity \\
\hline 1 & $6 e 7 e-23$ & -105.42 & -83.3015 & -2.3003 & 6e7e_36 & -6.9 \\
\hline 2 & $6 e 7 e-51$ & -104.935 & -86.2557 & -0.4690 & 6e7e_37 & -6.9 \\
\hline 3 & $6 e 7 e-32$ & -103.832 & -81.4928 & -5.9129 & 6e7e_39 & -6.9 \\
\hline 4 & $6 e 7 e-16$ & -102.325 & -81.2418 & -9.2016 & $6 e 7 e_{-} 44$ & -6.8 \\
\hline 5 & $6 e 7 e-44$ & -101.187 & -81.2352 & -2.8332 & $6 e 7 e \_50$ & -6.8 \\
\hline 6 & 6e7e-0 & -101.058 & -78.2991 & -1.1185 & 6e7e_11 & -6.7 \\
\hline 7 & 6e7e-35 & -100.81 & -74.1065 & -2.7562 & 6e7e_20 & -6.7 \\
\hline 8 & $6 e 7 e-48$ & -100.468 & -83.5565 & -4.8169 & 6e7e_38 & -6.6 \\
\hline 9 & $6 e 7 e-27$ & -99.6987 & -47.8776 & -5.9033 & $6 e 7 e \_4$ & -6.5 \\
\hline 10 & $6 e 7 e-15$ & -99.0472 & -59.3321 & -7.1583 & 6e7e_13 & -6.5 \\
\hline 11 & $6 e 7 e-41$ & -97.9657 & -83.8199 & -8.4460 & 6e7e_17 & -6.5 \\
\hline 12 & $6 e 7 e-34$ & -97.7763 & -75.7789 & -2.5000 & 6e7e_29 & -6.5 \\
\hline 13 & 6e7e-31 & -97.7655 & -71.8349 & -4.6374 & 6e7e_30 & -6.5 \\
\hline 14 & $6 e 7 e-29$ & -97.5903 & -80.7864 & -1.3863 & $6 e 7 e \_32$ & -6.5 \\
\hline 15 & $6 e 7 e-25$ & -97.1211 & -76.7611 & -4.3095 & 6e7e_33 & -6.5 \\
\hline 16 & $6 e 7 e-5$ & -97.0019 & -78.9432 & -2.5118 & $6 e 7 e \_43$ & -6.5 \\
\hline 17 & $6 e 7 e-43$ & -96.9476 & -65.1119 & -2.1904 & 6e7e_6 & -6.4 \\
\hline 18 & 6e7e-55 & -96.5008 & -80.0093 & -4.9261 & $6 e 7 e_{-} 16$ & -6.4 \\
\hline 19 & $6 e 7 e-42$ & -96.1401 & -61.68 & -2.5000 & 6e7e_21 & -6.4 \\
\hline 20 & $6 e 7 e-30$ & -96.0124 & -79.8537 & -1.9294 & $6 e 7 e \_26$ & -6.4 \\
\hline 21 & $6 e 7 e-37$ & -96.0051 & -79.1085 & -8.6238 & $6 e 7 e \_42$ & -6.4 \\
\hline 22 & $6 e 7 e-50$ & -95.9272 & -80.5706 & -5.0000 & 6e7e_51 & -6.4 \\
\hline 23 & 6e7e-39 & -95.494 & -73.5631 & -10.064 & 6e7e_1 & -6.3 \\
\hline 24 & $6 e 7 e-47$ & -94.6542 & -44.1998 & -5.6681 & 6e7e_18 & -6.3 \\
\hline 25 & $6 e 7 e-46$ & -93.8322 & -62.9706 & -8.4617 & 6e7e_2 & -6.2 \\
\hline 26 & $6 e 7 e-26$ & -93.7623 & -80.0366 & -1.4509 & 6e7e_5 & -6.2 \\
\hline 27 & $6 e 7 e-11$ & -93.429 & -59.9426 & -5.2496 & 6e7e_10 & -6.2 \\
\hline 28 & $6 e 7 e-3$ & -92.5362 & -77.3104 & -1.9807 & 6e7e_23 & -6.2 \\
\hline 29 & 6e7e-36 & -92.5281 & -50.0261 & -1.8100 & 6e7e_25 & -6.2 \\
\hline 30 & 6e7e-7 & -92.0915 & -73.6281 & -1.6712 & $6 e 7 e \_49$ & -6.2 \\
\hline 31 & $6 e 7 e-14$ & -91.8754 & -59.7878 & -5.9914 & 6e7e_3 & -6.1 \\
\hline 32 & $6 e 7 e-24$ & -91.383 & -75.9929 & -1.7595 & 6e7e_7 & -6.1 \\
\hline 33 & $6 e 7 e-13$ & -90.7777 & -78.6832 & -1.1915 & $6 e 7 e \_22$ & -6.1 \\
\hline 34 & $6 e 7 e-1$ & -89.6732 & -73.1549 & -2.8683 & $6 e 7 e \_27$ & -6.1 \\
\hline 35 & $6 e 7 e-21$ & -88.9992 & -71.4621 & -3.0701 & 6e7e_34 & -6.1 \\
\hline 36 & $6 e 7 e-10$ & -88.9228 & -76.5735 & -3.2483 & 6e7e_56 & -6.1 \\
\hline 37 & $6 e 7 e-28$ & -88.1999 & -54.2836 & -2.0728 & $6 e 7 e \_14$ & -6 \\
\hline 38 & $6 e 7 e-53$ & -85.632 & -70.8852 & -3.0808 & $6 e 7 e \_40$ & -6 \\
\hline 39 & 6e7e-54 & -85.2067 & -70.4645 & -2.6669 & $6 e 7 e \_41$ & -6 \\
\hline 40 & $6 e 7 e-12$ & -84.9434 & -68.4636 & -2.2346 & $6 e 7 e \_48$ & -6 \\
\hline 41 & $6 e 7 e-8$ & -84.2814 & -72.91 & -5.1099 & $6 e 7 e \_54$ & -6 \\
\hline 42 & $6 e 7 e-6$ & -84.2788 & -76.5631 & -5.6531 & 6e7e_55 & -6 \\
\hline 43 & $6 e 7 e-9$ & -83.9689 & -49.0408 & -3.0917 & 6e7e_57 & -6 \\
\hline 44 & 6e7e-18 & -83.7369 & -67.9812 & -1.5962 & 6e7e_19 & -5.9 \\
\hline 45 & $6 e 7 e-22$ & -83.2384 & -54.5351 & -8.8782 & $6 e 7 e \_28$ & -5.9 \\
\hline 46 & $6 e 7 e-20$ & -83.1924 & -73.3381 & -2.5000 & $6 e 7 e \_46$ & -5.9 \\
\hline 47 & $6 e 7 e-40$ & -83.1795 & -68.9391 & -10.526 & 6e7e_53 & -5.9 \\
\hline 48 & $6 e 7 e-45$ & -83.109 & -59.1662 & -7.3442 & 6e7e_58 & -5.9 \\
\hline 49 & 6e7e-19 & -82.4367 & -64.012 & -2.7144 & 6e7e_9 & -5.8 \\
\hline
\end{tabular}


Table 5 (continued)

\begin{tabular}{|c|c|c|c|c|c|c|}
\hline Positions & Ligand & MolDock score & Rerank score & HBond & $\begin{array}{l}\text { AutoDock vina: } \\
\text { ligand }\end{array}$ & Binding affinity \\
\hline 50 & $6 e 7 e-4$ & -80.9586 & -69.733 & -0.8362 & 6e7e_12 & -5.8 \\
\hline 51 & $6 e 7 e-38$ & -80.7574 & -64.5247 & -9.0498 & 6e7e_15 & -5.8 \\
\hline 52 & $6 e 7 e-33$ & -80.4312 & -69.4863 & -6.9611 & $6 e 7 e \_31$ & -5.8 \\
\hline 53 & $6 e 7 e-52$ & -79.6886 & -67.2744 & -3.2095 & $6 e 7 e \_47$ & -5.8 \\
\hline 54 & $6 e 7 e-17$ & -79.4327 & -67.8454 & -7.1736 & $6 e 7 e_{-} 45$ & -5.7 \\
\hline 55 & $6 e 7 e-49$ & -79.0299 & -71.0073 & -3.8401 & $6 \mathrm{e} 7 \mathrm{e} \_8$ & -5.4 \\
\hline 56 & $6 e 7 e-2$ & -78.0893 & -70.0143 & -5.0968 & 6e7e_35 & -5.4 \\
\hline 57 & - & - & - & - & 6e7e_52 & -5.3 \\
\hline 58 & - & - & & - & 6e7e_24 & -5.1 \\
\hline
\end{tabular}

and acceptors of the selected compounds conforms to the rule of 5 (such as $\mathrm{H}-\mathrm{A} \leq 10 ; \mathrm{H}-\mathrm{D} \leq 5$ ); this shows that the compounds can influence absorption and permeation and also tend to have an increased chance of reaching the market except for the standards (Std2, Std3, and Std4) as shown in Table 6. The two descriptors (1) rotatable bonds $\leq 10$ and (2) total polar surface area $\leq 140 \AA^{2}$ are identified as Veber's rule [26] concerning the oral bioavailability of the drug. Compound 44 and the standards (Std2, Std3, and Std4) violate the total polar surface area as shown in Table 6 with their values more than the standard range.

\section{Drug-likeness and lipophilicity analysis of the selected compounds and standards}

From Table 7, all the selected compounds having their ligand efficiency (LE) values greater than 0.3 (LE recommended values $\geq 3$ ) are qualified as a hit, while compound 23 is the most potent of all the selected compounds. For other bioactivity parameters such as ligand lipophilicity efficiency (LLE) and ligand-efficiency-dependent lipophilicity (LELP), their recommended values for a hit are $\geq 5$ and -10 to 10 , respectively [30-32]. The LLE values were observed for all the selected compounds, and compounds 16,44 , and 51 are within the recommended range. All the selected compounds obey (LELP) recommended value except compound 36 and compound 37 with LELP values of 20.177 and 14.208 , respectively (Table 7 ).

\section{Toxicity analysis of the selected compounds and standards}

The toxicity, total surface area, and relative polar surface area analysis of the selected compounds was performed using the DataWarrior package. All the selected compounds have no toxicity risk, except compound 16 which has high mutagenic and low irritant, while compound 32 toxicity risk factors were high in tumorigenic, reproductive effects, and irritant (Table 8).
The overall theoretical ADMET properties justify that compounds 23, 44, and 51 showed potential lead-like features and can be used for further assessment for Chlamydia trachomatis treatment.

\section{Clearances and computational data designed}

The golden triangle [33] is a visualization tool that helps medicinal chemists find metabolically stable, permeable, and potent drug candidates by combining in vitro permeability, in vitro clearance, and computational data. Moving the design properties into a region with a baseline of $\operatorname{cog} \mathrm{P}=-2$ to 5 at $\mathrm{MW}=200$ and a peak of 450 gives a triangular shape termed the golden triangle, which increases the probability of success in maximizing potency, stability, and permeability. For our selected compounds and standard drugs, it is apparent that compounds $16,23,44$, and 51 have good permeability and low clearance because they are concentrated within the golden triangle area (Fig. 7). These compounds (16, 23, $44,51)$ have the highest probability of success in maximizing potency, stability, and permeability.

Because they are concentrated within the golden triangle area, compounds $16,23,44$, and 51 have strong permeability and low clearance for our selected compounds and standard medications (Fig. 7).

\section{Molecular dynamics simulations}

The molecular dynamics simulations are widely used to investigate the behavioral and dynamical characteristics of the protein-ligand complex. The MD simulations of the proposed docked ligand were explored for $1 \mathrm{~ns}$. Several parameters such as kinetic energy, total energy, and potential energy were obtained from the MD simulation trajectory. Each of the parameters explains the stability of the complex in dynamics states. Compound 44 came first with iGemdock with a total energy of -87.383 , fifth with MVD with MolDock score of --101.325 , and second with AutoDock Vina with PyRx with a binding 

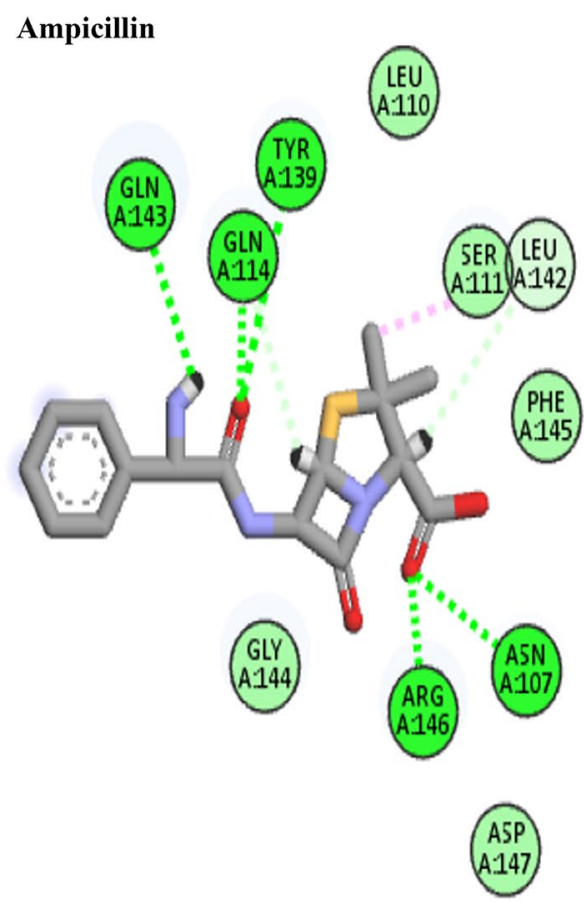

Interactions

\section{Oxytetracycline}

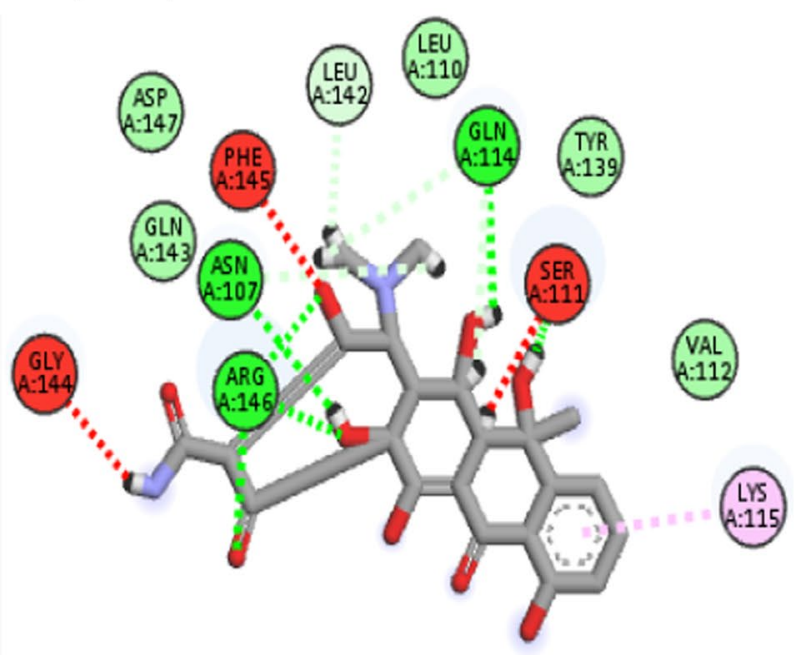

Interactions

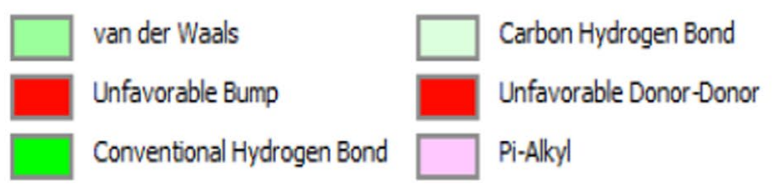

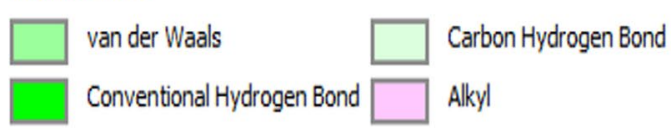

Chlortetracycline

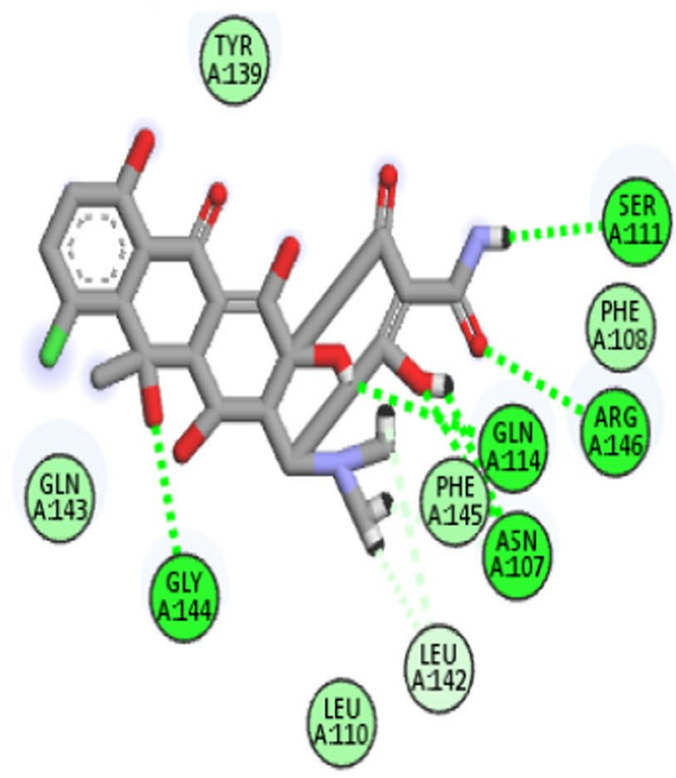

Interactions

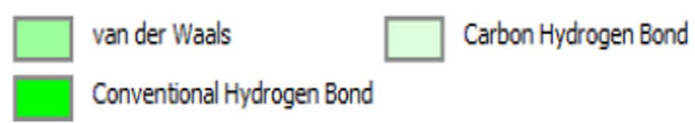

Ceftriaxone

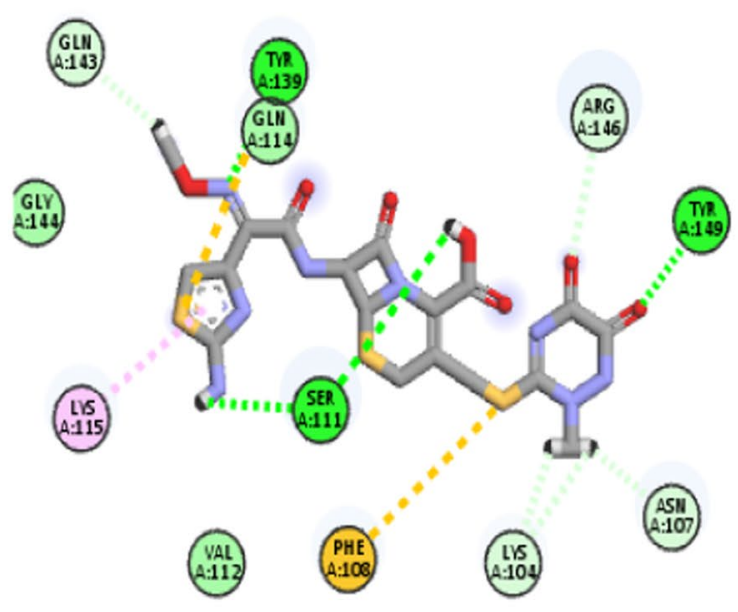

Interactions

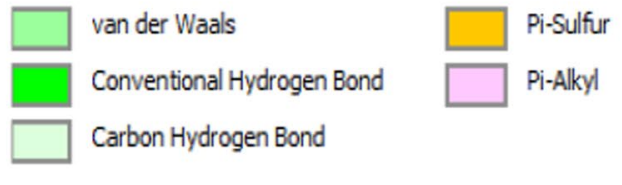

Fig. $32 D$ diagram of reference drugs and the crystal structure of IncA soluble domain interactions 


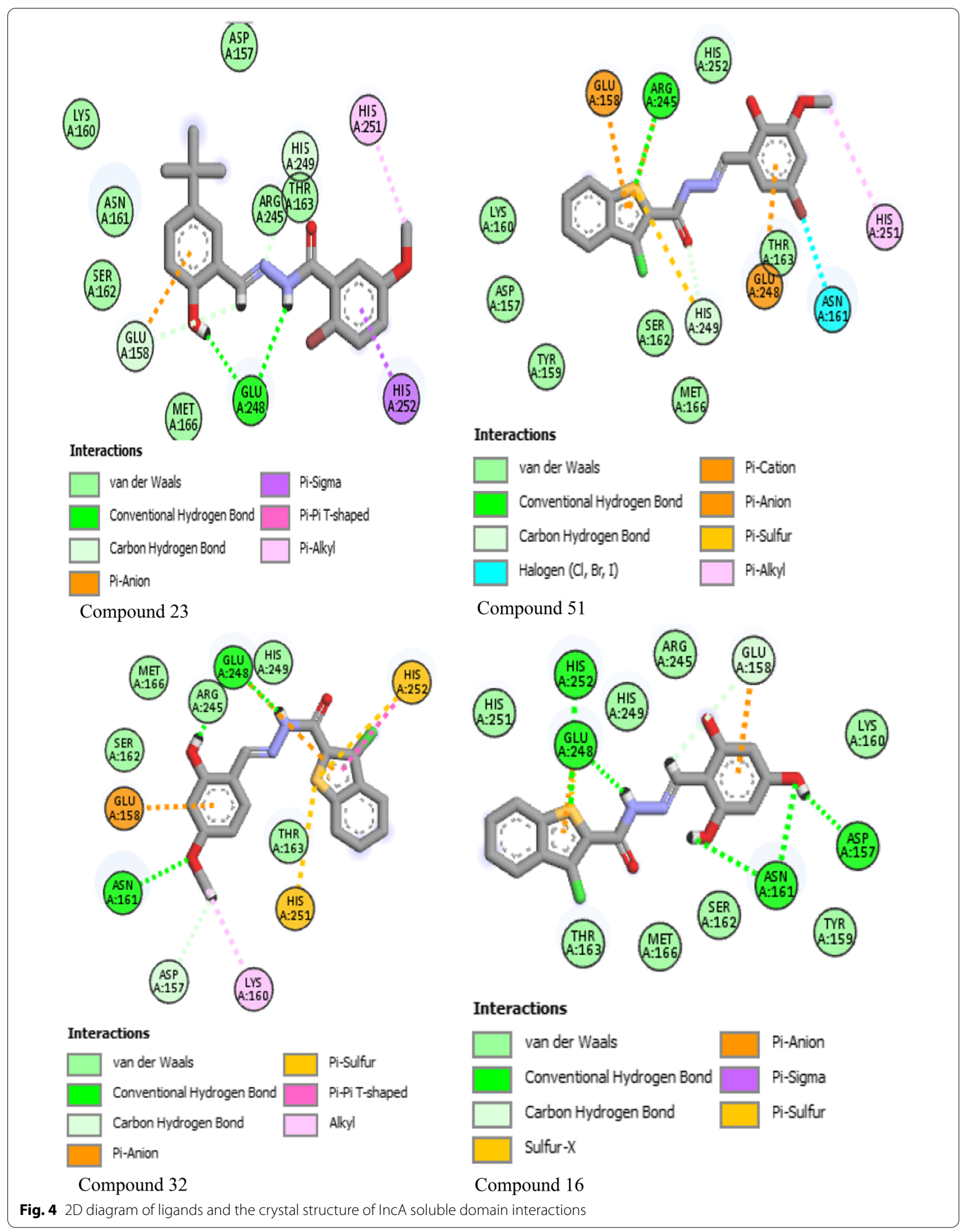




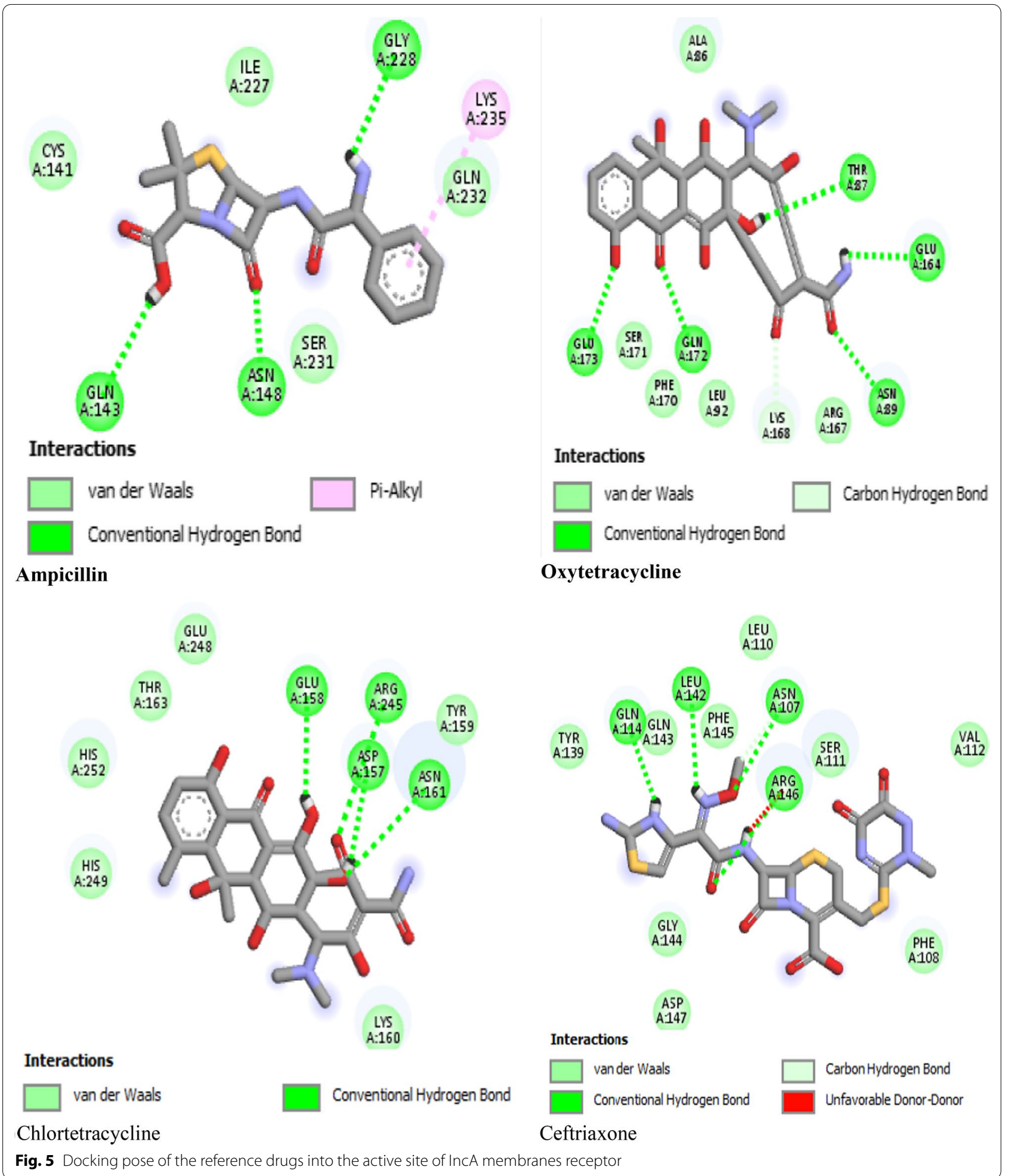

affinity value of $-6.8 \mathrm{kcal} / \mathrm{mol}$. These compounds also fit the Lipinski rule of 5 and also Veber rules. Even though compound 44 did not fit with one criterion in Veber's rules (TPSA), it has no mutagenic, tumorigenic, irritant, and developmental toxicity properties. It also passes lipophilicity indices (LE, LLE, and LELP) [34] and also falls within the golden triangle that was used for 1-ns MD simulations. Figure $8 \mathrm{~A}$ shows the variation in kinetic 


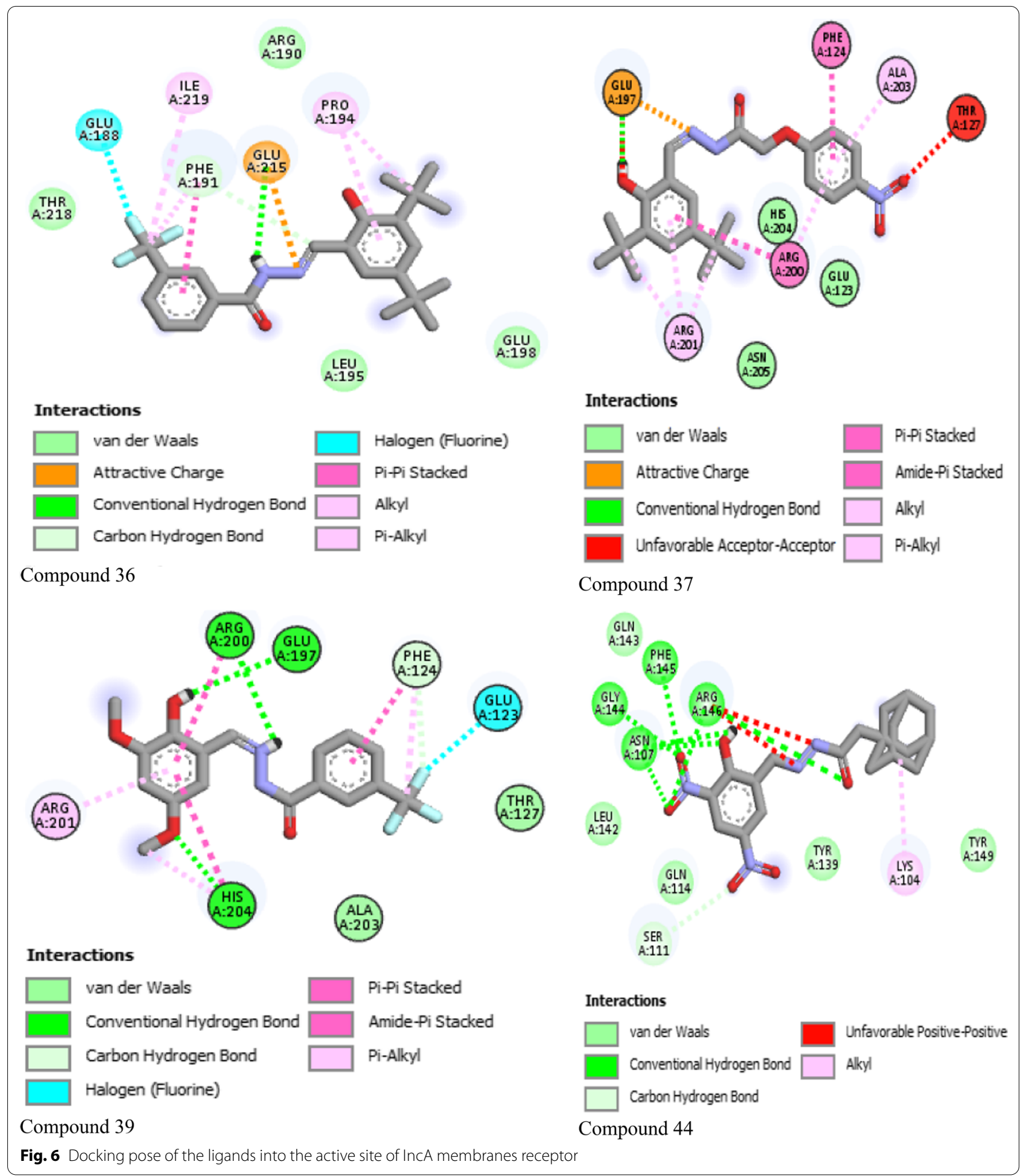

energy versus time in $1 \mathrm{~ns}$ of MD simulations. It shows a fluctuation at about $0.89 \mathrm{~ns}$ of the MD simulations. In Fig. $8 \mathrm{~B}$ and $\mathrm{C}$, the total energy and the potential energy versus time in 1-ns MD simulations show a fluctuation at about 0.8-ns MD simulations. After 500,000 runs (1 ns) using the NAMD package, the kinetic, total, and potential energy values are 51,926.64, $-234,493.11$, and $-286,419.79 \mathrm{kcal} / \mathrm{mol}$, respectively. These proofs show 
Table 6 Physicochemical properties of selected compounds in comparison with standard drugs

\begin{tabular}{|c|c|c|c|c|c|c|c|c|}
\hline Cpd no & MW & cLogP & cLogS & $\mathrm{H}-\mathrm{A}$ & $H-D$ & Violation & TPSA & R-Bond \\
\hline 16 & 315.284 & 1.864 & -3.903 & 8 & 2 & Nil & 116.74 & 5 \\
\hline 23 & 341.188 & 2.992 & -4.374 & 6 & 2 & Nil & 115.71 & 3 \\
\hline 32 & 354.148 & 3.146 & -5.357 & 7 & 2 & Nil & 107.51 & 4 \\
\hline 36 & 420.473 & 6.868 & -6.523 & 4 & 2 & 1 & 61.69 & 6 \\
\hline 37 & 427.499 & 4.673 & -5.985 & 8 & 2 & $\mathrm{Nil}$ & 116.74 & 8 \\
\hline 39 & 368.31 & 3.564 & -4.239 & 6 & 2 & Nil & 80.15 & 6 \\
\hline 44 & 402.406 & 1.920 & -5.6 & 10 & 2 & Nil & 153.33 & 6 \\
\hline 50 & 393.236 & 3.618 & -4.216 & 6 & 3 & $\mathrm{Nil}$ & 91.15 & 6 \\
\hline 51 & 375.336 & 1.369 & -3.701 & 10 & 2 & Nil & 135.2 & 8 \\
\hline Std 1 & 349.41 & -1.657 & -1.565 & 7 & 3 & Nil & 138.02 & 4 \\
\hline $\mathrm{Std} 2$ & 460.438 & -2.184 & -1.43 & 11 & 7 & 2 & 210.85 & 2 \\
\hline $\mathrm{Std} 3$ & 554.588 & -3.011 & -2.953 & 15 & 4 & 2 & 287.82 & 8 \\
\hline Std 4 & 494.883 & -1.578 & -2.166 & 11 & 7 & 2 & 201.85 & 2 \\
\hline
\end{tabular}

$\mathrm{MW}=$ molecular weight $\mathrm{cLog} \mathrm{P}=$ calculated $\log \mathrm{P} ; \mathrm{sLogS}=$ solubility $\mathrm{H}-\mathrm{A}=$ hydrogen bond acceptor; $\mathrm{H}-\mathrm{D}=$ hydrogen bond donor; $\mathrm{TPSA}=$ total polar surface area; R-Bond = rotatable bond; Std1 = ampicillin; Std2 = oxytetracycline; Std3 = chlortetracycline; Std4 = ceftriaxone

Table 7 Lipophilicity analysis of the selected compounds in comparison with standard drugs

\begin{tabular}{|c|c|c|c|c|c|c|c|}
\hline Cpd no & $\mathrm{DL}$ & LE & LLE & LELP & S-index & MolFle & Mol.Com \\
\hline 16 & -0.833 & 0.465 & 5.932 & 4.009 & 0.565 & 0.384 & 0.754 \\
\hline 23 & -0.855 & 0.552 & 4.646 & 5.425 & 0.579 & 0.320 & 0.682 \\
\hline 32 & -0.754 & 0.447 & 4.349 & 7.038 & 0.522 & 0.387 & 0.762 \\
\hline 36 & -6.115 & 0.340 & 0.576 & 20.177 & 0.467 & 0.436 & 0.798 \\
\hline 37 & -4.090 & 0.329 & 2.759 & 14.208 & 0.548 & 0.445 & 0.759 \\
\hline 39 & -2.876 & 0.391 & 3.845 & 9.117 & 0.538 & 0.444 & 0.778 \\
\hline 44 & -0.472 & 0.348 & 5.436 & 5.518 & 0.483 & 0.440 & 0.836 \\
\hline 50 & 1.353 & 0.417 & 3.683 & 8.669 & 0.667 & 0.414 & 0.720 \\
\hline 51 & -0.898 & 0.371 & 5.923 & 3.695 & 0.630 & 0.415 & 0.732 \\
\hline Std 1 & 9.365 & $\mathrm{Nil}$ & $\mathrm{Nil}$ & Nil & 0.542 & 0.381 & 0.895 \\
\hline $\mathrm{Std} 2$ & 5.166 & Nil & Nil & Nil & 0.364 & 0.328 & 1.088 \\
\hline Std3 & 16.694 & Nil & $\mathrm{Nil}$ & Nil & 0.528 & 0.388 & 0.959 \\
\hline Std4 & 5.216 & Nil & $\mathrm{Nil}$ & $\mathrm{Nil}$ & 0.353 & 0.326 & 1.106 \\
\hline
\end{tabular}

DL, drug-likeness; LE, ligand efficiency; LLE, ligand lipophilic efficiency; LELP, ligand efficiency dependent lipophilicity; S-index, shape index; MolFex, molecular flexibility; Mol.com, molecular complexity;Std1, ampicillin; Std2, oxytetracycline; Std3, chlortetracycline; Std4, ceftriaxone

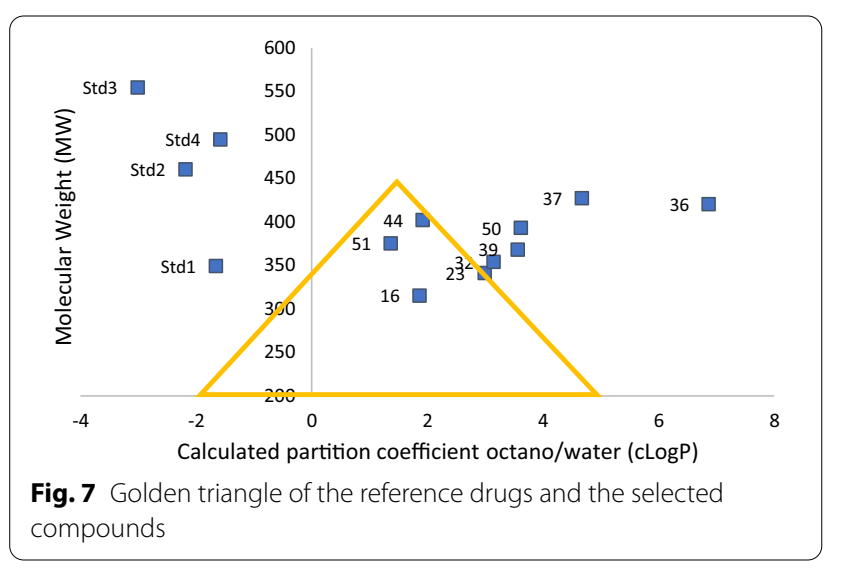

that energy conservation was satisfied in MD simulations. The binding site residues of compound 44 predicted by MD simulations yield 11 amino acid residues in the binding pocket, namely Ser111, Gln114, Asn107, Leu142, Gly144, Gln143, Lys104, Tyr149, Phe108, Phe145, and Arg146 (Fig. 8D). After a close look at compound 44 complex during MD simulations with the initial molecular docking analysis (Fig. 6), the simulated compound 44 complex adopts a similar binding pocket with the docking complex. The conventional hydrogen bonds, the van der Waals interactions, and the carbon-hydrogen bond observed in the docking complex were monitored. It was observed that the binding interactions of the 

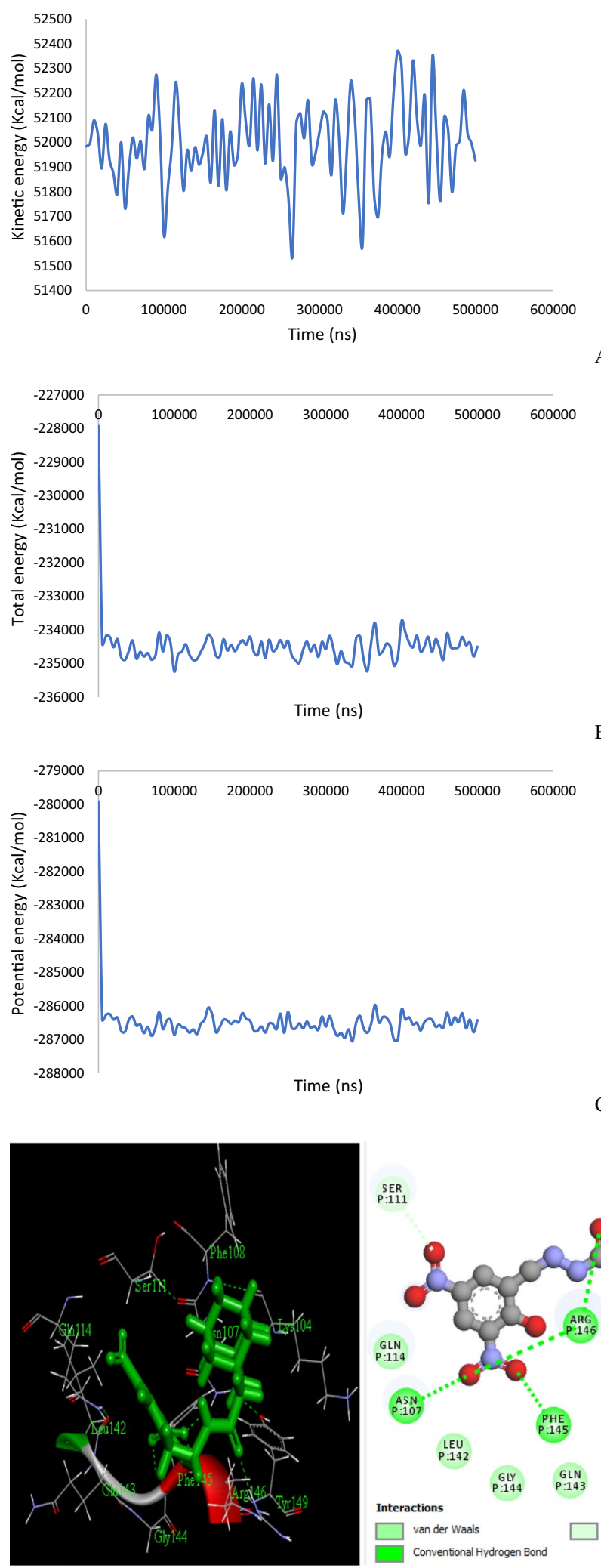

S:ER

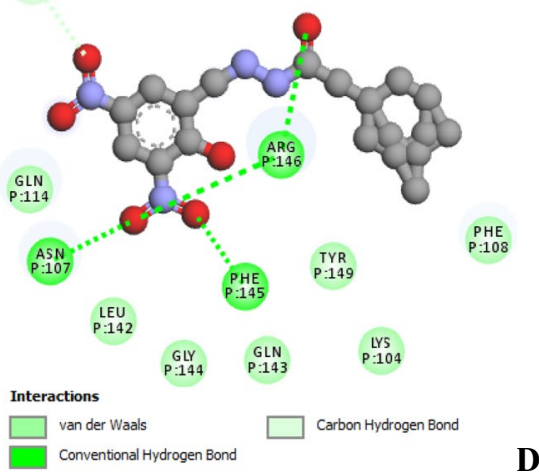

Fig. 8 Interaction of the simulated complex 
Table 8 Toxicity risk of selected compounds in comparison with standard drugs

\begin{tabular}{|c|c|c|c|c|c|c|}
\hline Cpd no & Mutagenic & Tumorigenic & Rep-eff & Irritant & TSA & RPSA \\
\hline 16 & High & None & None & Low & 239.27 & 0.374 \\
\hline 23 & None & None & None & None & 217.69 & 0.420 \\
\hline 32 & None & High & High & High & 247.85 & 0.321 \\
\hline 36 & None & None & None & None & 317.18 & 0.155 \\
\hline 37 & None & None & None & None & 335.15 & 0.267 \\
\hline 39 & None & None & None & None & 267.32 & 0.259 \\
\hline 44 & None & None & None & None & 284.65 & 0.386 \\
\hline 50 & None & None & None & None & 268.1 & 0.269 \\
\hline 51 & None & None & None & None & 285.29 & 0.384 \\
\hline Std 1 & None & None & None & None & 238.58 & 0.419 \\
\hline Std2 & None & None & None & None & 296.37 & 0.461 \\
\hline Std3 & None & None & None & None & 365.48 & 0.610 \\
\hline Std4 & None & None & None & None & 311.79 & 0.438 \\
\hline
\end{tabular}

Rep-Eff, reproductive effective; TSA, total surface area; RPSA, relative polar surface area; Std1, ampicillin; Std2, oxytetracycline; Std3, chlortetracycline; Std4, ceftriaxone

docking complex (Fig. 6) were reproduced in MD simulations (Fig. 8D). Compound 44 showed four conventional hydrogen bonds, two with Arg146, one each with Asn107 and Phe145, respectively, and one carbon-hydrogen bond with Ser111. The complex stabilizes its interactions with the binding pocket forming van der Waals interactions with the non-polar surfaces of the active site receptor with the amino acid residues (e.g., Gln114, Gln143, Leu142, Gly144, Lys104, Tyr149, and Phe108).

\section{Conclusions}

Herein, molecular docking, ADMET, golden triangle, and MD simulation studies were performed on a series of salicylidene acylhydrazides derivatives against Chlamydia trachomatis inhibitors. Three types of powerful docking software (namely MVD, iGemDock, and PyRx) with different algorithms were used to screen the most potent compounds. Docking studies confirm the potential of the nine compounds as novel inhibitors of the Chlamydia trachomatis receptor. Besides that, investigated compounds were subjected to the drug-likeness evaluation and golden triangle analysis. The findings revealed that the majority of the compounds would not be orally bioavailable rather would have clearance issues. Compound 44 passes all the quality assurance tests proposed by the model. For further investigation of binding modes of compound 44 and to explain the effects of the compound binding on protein conformation, 1-ns MD simulations were executed. At the end of the MD simulations, a similar position and orientation of the compound in the binding pocket were observed. This significant finding indicated that using MD simulations following ligand docking was beneficial. The nine anticipated salicylidene acylhydrazides inhibitors were predicted through computational techniques; hence, additional experimental validation would bring fresh insight on these compounds toward designing inhibitory drug molecules against common pathogens of Chlamydia trachomatis.

\section{Abbreviations}

STD: Sexually transmitted disease; CDC: Centers for Disease Control and Prevention; MD: Molecular dynamics; VMD: Van der Waals; WHO: World Health Organization; ADMET: Absorption, distribution, metabolism, elimination, and toxicity; MW: Molecular weight; CLogP: Calculated LogP; sLogS: Solubility; H-A: Hydrogen bond acceptor; H-D: Hydrogen bond donor; TPSA: Total polar surface area; R-Bond: Rotatable bond; DL: Drug-likeness; LE: Ligand efficiency; LLE: Ligand lipophilic efficiency; LELP: Ligand efficiency-dependent lipophilicity; S-index: Shape index; MolFex: Molecular flexibility; Mol.com: Molecular complexity; Rep-Eff: Reproductive effective; TSA: Total surface area; RPSA: Relative polar surface area; Std1: Ampicillin; Std2: Oxytetracycline; Std3: Chlortetracycline; Std4: Ceftriaxone.

\section{Acknowledgements}

The authors gratefully acknowledge the technical effort of Adawara Samuel Ndaghiya, Department of Pure and Applied Chemistry, University of Maiduguri, Borno State, Nigeria.

\section{Authors' contributions}

EIE designed and wrote the manuscript, and AU, GAS, and PAM supervised and carried out the statistical analysis. All authors read and approved the final manuscript.

\section{Funding}

Not applicable.

Availability of data and materials

Not applicable.

\section{Declarations}

Ethics approval and consent to participate

Not applicable.

Consent for publication

Not applicable. 


\section{Competing interests}

The authors declare that they have no competing interests.

\section{Author details}

${ }^{1}$ Department of Pure and Applied Chemistry, Faculty of Science, University of Maiduguri, P.M.B. 1069, Maiduguri, Borno State, Nigeria. ${ }^{2}$ Department of Chemistry, Faculty of Physical Sciences, Ahmadu Bello University, P.M.B. 1044, Zaria, Kaduna State, Nigeria.

Received: 22 July 2021 Accepted: 11 October 2021

Published online: 30 October 2021

\section{References}

1. Abdelsayed S, Ha Duong NT, Hai J, Hémadi M, El Hage Chahine JM, Verbeke P, Serradji N (2014) Design and synthesis of 3-isoxazolidone derivatives as new Chlamydia trachomatis inhibitors. Bioorg Med Chem Lett 24:3854-3860. https://doi.org/10.1016/j.bmcl.2014.06.056

2. Edache El, Uzairu A, Mamza PA, Shallangwa GA (2020) Computational modeling and molecular dynamics simulations of thiazolino 2-pyridone amide analog compounds as Chlamydia trachomatis inhibitor. J Chem Lett 1:123-138

3. Gaydos C, Essig A (2015) Chlamydiaceae. In: Jorgensen JH, Carroll KC, Funke G, Pfaller MA, Landry ML, Richter SS, Warnock DW (eds) Manual of clinical microbiology, 11 th edn. John Wiley \& Sons, Inc., pp 1106-1121

4. WHO (2001) Global prevalence and incidence of selected curable sexually transmitted infections: overview and estimates. World Health Organization, Geneva

5. Workowski KA, Berman SM (2011) Centers for disease control and prevention sexually transmitted disease treatment guidelines. Clin Infect Dis 53(suppl_3):S59-S63

6. Cordova D, Mendoza Lua F, Muñoz-Velázquez J, Street K, Bauermeister JA, Fessler K et al (2019) A multilevel mHealth drug abuse and STI/HIV preventive intervention for clinic settings in the United States: a feasibility and acceptability study. PLoS ONE 14(8):e0221508

7. CDC (2011) Sexually transmitted disease surveillance, centers for disease control and prevention. US Department of Health and Human Services, Atlanta, pp 1-155

8. Longo DL, Fauci AS, Kasper DL, Hauser SL, Jameson JL, Loscalzo J (2014) Harrison's principles of internal medicine, 19th edn. McGraw-Hill Medical, New York

9. Lutter E, Martens C, Hackstadt T (2012) Evolution and conservation of predicted inclusion membrane proteins in chlamydiae. Comp Funct Genom 2012:362104

10. Cingolani G, McCauley M, Lobley A, Bryer AJ, Wesolowski J, Greco DL et al (2019) Structural basis for the homotypic fusion of chlamydial inclusions by the SNARE-like protein IncA. Nat Commun 10(1):1-12. https://doi.org/ 10.1038/s41467-019-10806-9

11. Madonna R, Novo G, Balistreri CR (2016) Cellular and molecular basis of the imbalance between vascular damage and repair in aging and agerelated diseases: as biomarkers and targets for new treatments. Mech Ageing Dev 159:22-30. https://doi.org/10.1016/j.mad.2016.03.005

12. Baig MH, Ahmad K, Rabbani G, Danishuddin M, Choi I (2018) Computeraided drug design and its application to the development of potential drugs for neurodegenerative disorders. Curr Neuropharmacol 16:740748. https://doi.org/10.2174/1570159X15666171016163510

13. Bassetti M, Ginocchio F, Mikulska M (2011) New treatment options against gram-negative organisms. Crit Care 15:215. https://doi.org/10. $1186 /$ cc9997

14. Zabawa TP, Pucci MJ, Parr TR Jr, Lister T (2016) Treatment of gram-negative bacterial infections by potentiation of antibiotics. Curr Opin Microbiol 33:7-12

15. Chelazzi C, Pettini E, Villa G, Gaudio ARD (2015) Epidemiology, associated factors and outcomes of ICU-acquired infections caused by gram-negative bacteria in critically ill patients: an observational and retrospective study. BMC Anesthesiol 15:125

16. Ivády B, Kenesei É, Tóth-Heyn P, Kertész G, Tárkányi K, Kassa C et al (2016) Factors influencing antimicrobial resistance and outcome of
Gram-negative bloodstream infections in children. Infection 44(3):309321. https://doi.org/10.1007/s15010-015-0857-8

17. Kulén M, Núñez-Otero C, Cairns AG, Silver J, Lindgren AE, Wede E et al (2019) Methyl sulfonamide substituents improve the pharmacokinetic properties of bicyclic 2-pyridone based Chlamydia trachomatis inhibitors. MedChemComm 10(11):1966-1987. https://doi.org/10.1039/c9md00405j

18. Hadni H, Elhallaoui M (2020) 2D and 3D-QSAR, molecular docking and ADMET properties in silico studies of azaaurones as antimalarial agents. New J Chem. https://doi.org/10.1039/c9nj05767f

19. Edache El, Uzairu A, Mamza PA, Shallangwa GA (2021) Docking Simulations and Virtual Screening to find Novel Ligands for T3S in Yersinia pseudotuberculosis YPIII, A drug target for type III secretion (T3S) in the Gram-negative pathogen Yersinia pseudotuberculosis. Chem Rev Lett 4(3):13-144

20. Hsu KC, Chen YF, Lin SR, Yang JM (2011) iGemDock: a graphical environment of enhancing GEMDOCK using pharmacological interactions and post-screening analysis. BMC Bioinformatics 2(1):1-11

21. Kusumaningrum S, Budianto E, Kosela S, Sumaryono W, Juniarti F (2014) The molecular docking of 1,4-naphthoquinone derivatives as inhibitors of Polo-like kinase 1 using Molegro virtual docker. J App Pharm Sci 4(11):047-053

22. Trott O, Olson AJ (2009) AutoDock Vina: improving the speed and accuracy of docking with a new scoring function, efficient optimization, and multithreading. J Comput Chem 31:455-461. https://doi.org/10.1002/jcc. 21334

23. Humphrey W, Dalke A, Schulten K (1996) VMD: visual molecular dynamics J Mol Graph 14:33-38

24. Phillips JC, Braun R, Wang W, Gumbart J, Tajkhorshid E, Villa E, Chipot C, Skeel RD, Kale L, Schulten K (2005) Scalable molecular dynamics with NAMD. J Comput Chem 26:1781-1802

25. Lipinski CA, Lombardo F, Dominy BW, Feeney PJ (2001) Experimental and computational approaches to estimate solubility and permeability in drug discovery and development settings. Adv Drug Deliv Rev 46(1-3):3-26

26. Veber DF, Johnson SR, Cheng HY, Smith BR, Ward KW, Kopple KD (2002) Molecular properties that influence the oral bioavailability of drug candidates. J Med Chem 45(12):2615-2623

27. Fadel FZ, Tchouar N, Belaidi S, Soualmia F, Oukil O, Ouadah K (2021) Computational screening and QSAR study on a series of theophylline derivatives as aldh1a1 inhibitors. J Fundam Appl Sci 13(2):942-964. https://doi. org/10.4314/jfas.v13i2.17

28. Edache El, Uzairu A, Mamza PA, Shallangwa GA (2020) Molecular docking, molecular dynamics simulations, and ADME study to identify inhibitors of Crimean-Congo Hemorrhagic Fever (CCHF) viral ovarian tumor domain protease (vOTU). Chem Res J 5(5):16-30

29. Bergenhem N (2011) Preclinical candidate nomination and development. In: Tsaioun K, Kate SA (eds) ADMET for medicinal chemists. Wiley, Singapore, pp 399-415

30. Schultes S, De Graaf C, Haaksma EEJ, De Esch IJP, Leurs R, Kramer O (2010) Ligand efficiency as a guide in fragment hit selection and optimization. Drug Discov Today Technol 7:e157-e162. https://doi.org/10.1016/j.ddtec. 2010.11.003

31. Hopkins AL, Keserü GM, Leeson PD, Rees DC, Reynolds CH (2014) The role of ligand efficiency metrics in drug discovery. Nat Rev Drug Discov 13:105-121. https://doi.org/10.1038/nrd4163

32. Smida KB, Belaidi S, Benbrahim I, Boughdiri S (2015) Theoretical studies of structure/activity relationships applied to flavone derivate for drug discovery. Res J Pharm Biol Chem Sci 6:874-885

33. Johnson TW, Dress KR, Edwards M (2009) Using the golden triangle to optimize clearance and oral absorption. Bioorg Med Chem Lett 19:5560-5564. https://doi.org/10.1016/j.bmcl.2009.08.045

34. Keseru GM, Makara GM (2009) The influence of lead discovery strategies on the properties of drug candidates. Nat Rev Drug Discov 3:203-212. https://doi.org/10.1038/nrd2796

\section{Publisher's Note}

Springer Nature remains neutral with regard to jurisdictional claims in published maps and institutional affiliations. 